\title{
Convergent, Enantioselective Syntheses of Guanacastepenes A and E Featuring a Selective Cyclobutane Fragmentation
}

\author{
William D. Shipe and Erik J. Sorensen \\ Frick Chemical Laboratory, Princeton University, Princeton, New Jersey 08544-1009
}

\section{Supporting Information}

\section{General experimental details}

All reactions were carried out under an atmosphere of $\mathrm{Ar}$ or $\mathrm{N}_{2}$ unless otherwise specified. Tetrahydrofuran (THF), toluene, diethyl ether $\left(\mathrm{Et}_{2} \mathrm{O}\right)$, and methylene chloride $\left(\mathrm{CH}_{2} \mathrm{Cl}_{2}\right)$ were dried by passing through activated alumina columns. Commercial reagents of high purity were purchased and used without further purification, unless otherwise noted. Organolithium reagents were titrated using sec-butanol in ether, with 1,10-phenanthroline as an indicator. Reactions were monitored by thin-layer chromatography (TLC) carried out on $0.25 \mathrm{~mm}$ Merck HPTLC silica gel plates $\left(60 \mathrm{~F}_{254}\right)$ using UV light as a visualizing agent and aqueous ceric sulfate/phosphomolybdic acid or ethanolic $p$-anisaldehyde solution and heat as developing agents. E. Merck silica gel 60 (230-400 mesh) was used for flash column chromatography.

\section{Instrumentation}

FT-IR spectra were obtained on a Perkin-Elmer Paragon 500 FT-IR. NMR spectra were obtained on Bruker DRX-600, DRX-500, AMX-400, and Varian Inova-500, Inova-400, and Mercury-Vx-300 instruments and calibrated to the residual solvent peak. The multiplicities are abbreviated as follows: $\mathrm{s}=$ singlet, $\mathrm{d}=$ doublet, $\mathrm{t}=$ triplet, $\mathrm{m}=$ multiplet, app $\mathrm{s}=$ apparent singlet, app $\mathrm{d}=$ apparent doublet, app $\mathrm{t}=$ apparent triplet, $\mathrm{br}=$ 
broad signal. Optical rotations were recorded on a Perkin-Elmer model 241 polarimeter using a $1 \mathrm{~mL}, 1 \mathrm{dm}$ cell. Mass spectra were obtained using a Perkin-Elmer API Sciex single quadrupole instrument (ESI), an IonSpec Ultima FTMS instrument (MALDIFTMS), and a Kratos MS50 instrument (EI).

Experimental procedures and characterization data for the compounds described in this article as well as the compounds that were described in the preliminary communication [W. D. Shipe and E. J. Sorensen, Organic Letters 2002, 4, 2063-2066] are provided below.

Reaction sequence used to synthesize the C-ring, cyclohexenoid domain of the guanacastepenes: 

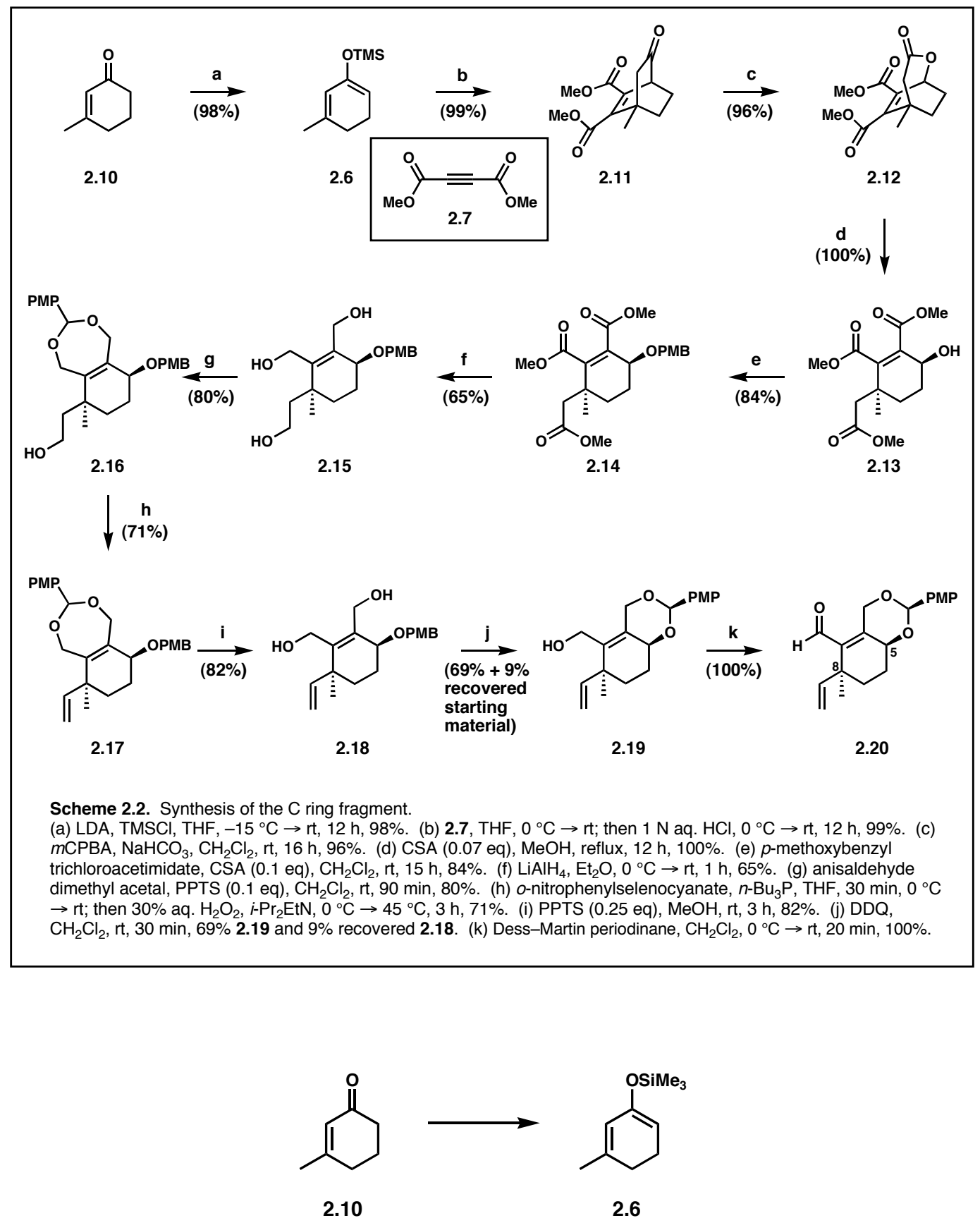

Silyl enol ether 2.6 (From Organic Letters 2002, 4, 2063-2066): A 500 mL flask was charged with diisopropylamine $(12.1 \mathrm{~g}, 16.8 \mathrm{~mL}, 120 \mathrm{mmol})$ in $200 \mathrm{~mL}$ dry THF. The flask was cooled to $0^{\circ} \mathrm{C}$ and a solution of $2.4 \mathrm{M} n$-BuLi in hexanes (46 mL, $110 \mathrm{mmol}$ ) was slowly added via syringe. The mixture was stirred at $0{ }^{\circ} \mathrm{C}$ for $30 \mathrm{~min}$, then 3 methylcyclohexenone $\mathbf{2 . 1 0}(11.0 \mathrm{~g}, 11.35 \mathrm{~mL}, 100 \mathrm{mmol})$ was added over a 5-minute 
period. After $15 \mathrm{~min}$, chlorotrimethylsilane $(16.3 \mathrm{~g}, 19.0 \mathrm{~mL}, 150 \mathrm{mmol})$ was quickly added and the mixture was stirred for $12 \mathrm{~h}$. Volatiles were removed in vacuo, the residue was filtered in pentane, and the filtrate was concentrated. The crude material was generally taken into the next reaction, but it could be distilled at $78^{\circ} \mathrm{C}$ at $15 \mathrm{Torr}$, in this case yielding $17.9 \mathrm{~g}(98 \%)$ of the known silyl enol ether $\mathbf{2 . 6}$ as a colorless oil.

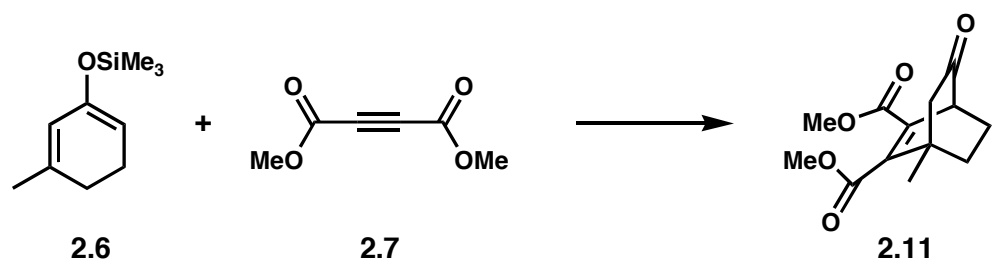

Ketone 2.11 (From Organic Letters 2002, 4, 2063-2066): Silyl enol ether 2.6 (17.9 g, $98.2 \mathrm{mmol}$ ) was placed in a $500 \mathrm{~mL}$ flask, dissolved in $50 \mathrm{~mL}$ dry THF, and cooled to 0 ${ }^{\circ} \mathrm{C}$. Dimethylacetylenedicarboxylate $2.7(14.0 \mathrm{~g}, 12.1 \mathrm{~mL}, 98.2 \mathrm{mmol})$ was then added and the mixture was allowed to slowly warm to rt. ${ }^{1} \mathrm{H}$ NMR after $24 \mathrm{~h}$ showed complete consumption of the starting materials. The mixture was again cooled to $0{ }^{\circ} \mathrm{C} .50 \mathrm{~mL}$ of $1 \mathrm{~N}$ aq. $\mathrm{HCl}$ was added under vigorous stirring. After 45 minutes, ${ }^{1} \mathrm{H}$ NMR of an aliquot showed complete hydrolysis of the silyl enol ether. The reaction was poured into $150 \mathrm{~mL}$ of saturated aq. $\mathrm{NaHCO}_{3} / \mathrm{pH} 7$ phosphate buffer. The mixture was extracted with $\mathrm{CH}_{2} \mathrm{Cl}_{2}$ (3x). Extracts were washed with brine, dried over $\mathrm{MgSO}_{4}$, and concentrated to give 24.5 $\mathrm{g}(99 \%)$ of ketone $\mathbf{2 . 1 1}$ as a colorless oil. TLC: $\mathrm{R}_{\mathrm{f}}=0.25$ (20\% EtOAc/hexanes); IR (film) 2953, 1723, 1435, 1259, $1072 \mathrm{~cm}^{-1} ;{ }^{1} \mathrm{H} \mathrm{NMR}\left(400 \mathrm{MHz}, \mathrm{CDCl}_{3}\right) \delta 3.83(\mathrm{~s}, 3 \mathrm{H})$, $3.76($ app t, $J=2.8 \mathrm{~Hz}, 1 \mathrm{H}), 3.74(\mathrm{~s}, 3 \mathrm{H}), 2.08(\mathrm{dd}, J=18.4,3.0 \mathrm{~Hz}, 1 \mathrm{H}), 1.99(\mathrm{~d}, J=$ 18.4, $1 \mathrm{H}), 1.97(\mathrm{~m}, 1 \mathrm{H}), 1.75(\mathrm{~m}, 1 \mathrm{H}), 1.66(\mathrm{~m}, 1 \mathrm{H}), 1.59(\mathrm{~m}, 1 \mathrm{H}), 1.28(\mathrm{~s}, 3 \mathrm{H}) ;{ }^{13} \mathrm{C}$ 
NMR $\left(100 \mathrm{MHz}, \mathrm{CDCl}_{3}\right) \delta 209.1,167.3,163.1,152.7,128.1,52.4,52.2,47.9,45.7$, 40.6, 32.2, 23.5, 20.6; HRMS (EI) calculated for [M] ${ }^{+}$252.0998, found 252.0997.

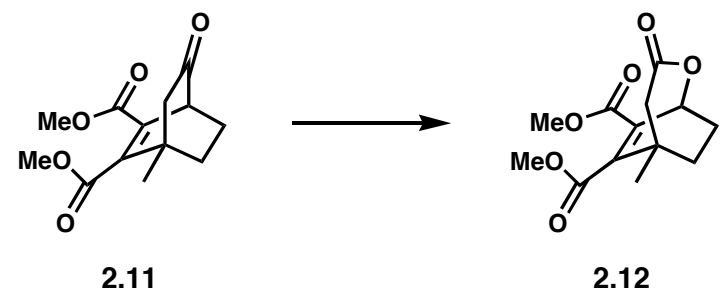

Lactone 2.12 (From Organic Letters 2002, 4, 2063-2066): To ketone 2.11 (37.6 g, 149 mmol) in $500 \mathrm{~mL} \mathrm{CH}_{2} \mathrm{Cl}_{2}$ was added recrystallized $m \mathrm{CPBA}(51.8 \mathrm{~g}, 300 \mathrm{mmol})$ and $\mathrm{NaHCO}_{3}(35.3 \mathrm{~g}, 420 \mathrm{mmol})$, and the mixture was stirred. The reaction was cooled to 0 ${ }^{\circ} \mathrm{C}$ after $12 \mathrm{~h}$, and $500 \mathrm{~mL}$ of saturated aqueous $\mathrm{Na}_{2} \mathrm{~S}_{2} \mathrm{O}_{3}$ was added to the thick, white reaction mixture. Solids were filtered, the layers were separated, and the aqueous layer was extracted with $\mathrm{CH}_{2} \mathrm{Cl}_{2}(2 \times 250 \mathrm{~mL})$. The combined organic layers were washed with brine, dried over $\mathrm{MgSO}_{4}$, and concentrated to afford $19.4 \mathrm{~g}$ of white crystalline lactone 2.12 after crystallization from $\mathrm{Et}_{2} \mathrm{O}$. The mother liquor was concentrated and purified by flash chromatography $\left(\mathrm{SiO}_{2}, 50 \rightarrow 55 \%\right.$ EtOAc/hexanes) to afford $18.9 \mathrm{~g}$ (total yield $38.3 \mathrm{~g}, \mathbf{9 6 \%}$ ) of lactone $\mathbf{2 . 1 2}$ as a white solid. The white solid could be recrystallized to give colorless crystals. $\mathrm{mp}=100{ }^{\circ} \mathrm{C} ;$ TLC: $\mathrm{R}_{\mathrm{f}}=0.20(50 \%$ EtOAc/hexanes); IR (film) 2954, 1725, 1646, 1259, 1121, 1071, $1029 \mathrm{~cm}^{-1}$; ${ }^{1} \mathrm{H}$ NMR $\left(400 \mathrm{MHz}, \mathrm{CDCl}_{3}\right): \delta 5.50(\mathrm{br} \mathrm{d}, J=4.8 \mathrm{~Hz}, 1 \mathrm{H}), 3.85(\mathrm{~s}, 3 \mathrm{H}), 3.78(\mathrm{~s}, 3 \mathrm{H}), 2.92(\mathrm{dd}$, $J=18.8,2.4 \mathrm{~Hz}, 1 \mathrm{H}), 2.69(\mathrm{~d}, J=18.8 \mathrm{~Hz}, 1 \mathrm{H}), 2.44(\mathrm{~m}, 1 \mathrm{H}), 2.00(\mathrm{~m}, 1 \mathrm{H}), 1.93(\mathrm{~m}, 1$ $\mathrm{H}), 1.74(\mathrm{~m}, 1 \mathrm{H}), 1.17(\mathrm{~s}, 3 \mathrm{H}) ;{ }^{13} \mathrm{C}$ NMR (100 MHz, $\left.\mathrm{CDCl}_{3}\right)$ : $\delta$ 169.7, 166.9, 163.0, 155.3, 128.8, 69.7, 52.7, 52.3, 48.0, 35.6, 32.2, 26.8, 24.3; HRMS (MALDI-FTMS) calculated for $[\mathrm{M}+\mathrm{Na}]^{+} 291.0839$, found 291.0838 . 


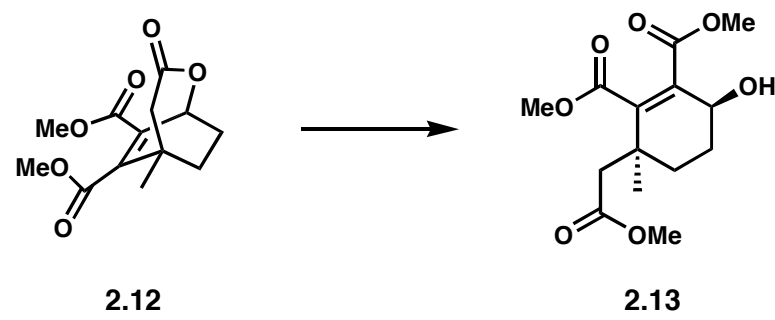

Hydroxytriester 2.13 (From Organic Letters 2002, 4, 2063-2066): Lactone 2.12 (25.7 $\mathrm{g}, 95.8 \mathrm{mmol}$ ) was placed in a $1 \mathrm{~L}$ flask, dissolved in $400 \mathrm{~mL} \mathrm{MeOH}$, and camphorsulfonic acid $(1.6 \mathrm{~g}, 7.0 \mathrm{mmol})$ was added. A reflux condenser was attached to the flask and the mixture was heated at reflux for $16 \mathrm{~h}$. $\mathrm{MeOH}$ was then removed in vacuo, and the residue was neutralized with saturated aq. $\mathrm{NaHCO}_{3}$. The mixture was extracted with $\mathrm{CH}_{2} \mathrm{Cl}_{2}(3 \mathrm{x})$, dried over $\mathrm{MgSO}_{4}$, and concentrated to afford $28.7 \mathrm{~g}(100 \%)$ of hydroxytriester $\mathbf{2 . 1 3}$ as a pale yellow oil. TLC: $\mathrm{R}_{\mathrm{f}}=0.40$ (35\% EtOAc/toluene); IR (film) 3494, 2953, 1726, 1436, 1260, 1067, $1025 \mathrm{~cm}^{-1} ;{ }^{1} \mathrm{H}$ NMR (400 MHz, $\left.\mathrm{CDCl}_{3}\right) \delta$ 4.56 (app t, $J=4.4 \mathrm{~Hz}, 1 \mathrm{H}), 3.752$ (s, $3 \mathrm{H}), 3.746(\mathrm{~s}, 3 \mathrm{H}), 3.64$ (s, $3 \mathrm{H}), 3.01(\mathrm{br} \mathrm{s}, 1 \mathrm{H})$, $2.62(\mathrm{~d}, J=16.0 \mathrm{~Hz}, 1 \mathrm{H}), 2.50(\mathrm{~d}, J=16.0 \mathrm{~Hz}, 1 \mathrm{H}), 2.25(\mathrm{~m}, 1 \mathrm{H}), 1.85(\mathrm{~m}, 2 \mathrm{H}), 1.45$ (m, $1 \mathrm{H}), 1.19$ (s, $3 \mathrm{H}) ;{ }^{13} \mathrm{C}$ NMR (100 MHz, $\left.\mathrm{CDCl}_{3}\right) \delta$ 171.5, 168.4, 166.7, 148.1, 131.4, 63.4, 52.4 , 52.1, 51.5, 43.0, 36.3, 29.4, 26.3, 25.0; HRMS (MALDI-FTMS) calculated for $[\mathrm{M}+\mathrm{Na}]^{+}$323.1101, found 323.1107.

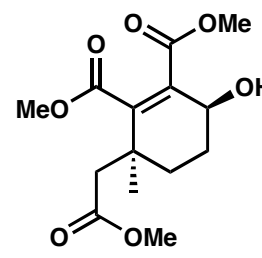

2.13

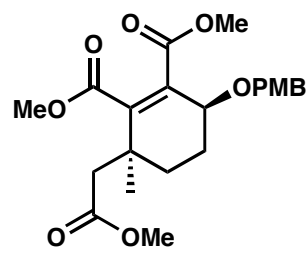

2.14 
PMB ether 2.14 (From Organic Letters 2002, 4, 2063-2066): Hydroxytriester 2.13 (28.2 g, $93.9 \mathrm{mmol}$ ) was dissolved in $300 \mathrm{~mL}$ dry $\mathrm{CH}_{2} \mathrm{Cl}_{2}$ in a $1 \mathrm{~L}$ flask. The solution was treated with $p$-methoxybenzyltrichloroacetimidate $(84.8 \mathrm{~g}, 61 \mathrm{~mL}, 300 \mathrm{mmol})$, then camphorsulfonic acid $(2.32 \mathrm{~g}, 10 \mathrm{mmol})$. After $36 \mathrm{~h}$, the reaction was concentrated and much of the trichloroacetamide byproduct was filtered off with hexanes. The filtrate was poured into $250 \mathrm{~mL}$ saturated aq. $\mathrm{NaHCO}_{3}$. The mixture was extracted with $\mathrm{CH}_{2} \mathrm{Cl}_{2}(3 \mathrm{x})$, dried over $\mathrm{MgSO}_{4}$, and concentrated to afford $35.7 \mathrm{~g}$ of crude PMB ether 2.14. Purification by flash chromatography $\left(\mathrm{SiO}_{2}, 20 \rightarrow 30 \%\right.$ EtOAc/hexanes, $200 \mathrm{~mL}$ fractions) on the crude product afforded $33.1 \mathrm{~g}$ (84\%) of PMB ether $\mathbf{2 . 1 4}$ as a pale yellow viscous oil. TLC: $R_{\mathrm{f}}=0.26$ (30\% EtOAc/hexanes); IR (film) 2951, 1728, 1514, 1434, 1248, 1070, $1032 \mathrm{~cm}^{-1} ;{ }^{1} \mathrm{H}$ NMR (400 MHz, $\left.\mathrm{CDCl}_{3}\right) \delta 7.23(\mathrm{~d}, J=8.8 \mathrm{~Hz}, 2 \mathrm{H}), 6.85(\mathrm{~d}, J$ $=8.8 \mathrm{~Hz}, 2 \mathrm{H}), 4.54(\mathrm{~d}, J=11.2 \mathrm{~Hz}, 1 \mathrm{H}), 4.47(\mathrm{~d}, J=11.2 \mathrm{~Hz}, 1 \mathrm{H}), 4.38($ app t, $J=5.8$ Hz, 1 H), 3.79 (s, 3 H), 3.74 (s, 3 H), 3.71 (s, 3 H), 3.64 (s, 3 H), 2.76 (d, J = 14.8 Hz, 1 H), $2.62(\mathrm{~d}, J=14.8 \mathrm{~Hz}, 1 \mathrm{H}), 2.10(\mathrm{~m}, 1 \mathrm{H}), 1.85(\mathrm{~m}, 2 \mathrm{H}), 1.44(\mathrm{~m}, 1 \mathrm{H}), 1.18(\mathrm{~s}, 3 \mathrm{H})$; ${ }^{13} \mathrm{C}$ NMR $\left(100 \mathrm{MHz}, \mathrm{CDCl}_{3}\right) \delta 171.3,168.1,167.2,159.1,146.5,132.9,130.3,129.4$, 113.6, 71.4, 71.3, 55.2, 52.1, 52.0, 51.4, 42.5, 36.3, 30.4, 24.1, 23.8; HRMS (MALDIFTMS) calculated for [M+Na] ${ }^{+}$443.1676, found 443.1683.

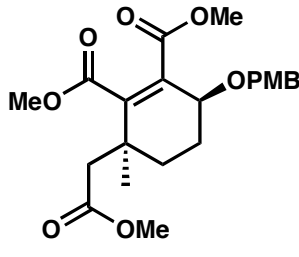

2.14

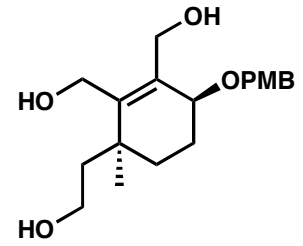

2.15 
Triol 2.15 (From Organic Letters 2002, 4, 2063-2066): To a $0{ }^{\circ} \mathrm{C}$ suspension of $1 \mathrm{M}$ lithium aluminum hydride in $\mathrm{Et}_{2} \mathrm{O}$ in a $1 \mathrm{~L}$ flask was added $\mathrm{PMB}$ ether 2.14 (33.0 g, 78.5 $\mathrm{mmol}$ ) in $250 \mathrm{~mL}$ dry $\mathrm{Et}_{2} \mathrm{O}$ via cannula over $3 \mathrm{~h}$. After the addition, the mixture was allowed to warm to $\mathrm{rt}$ and stir for $2 \mathrm{~h}$. The mixture was then cooled to $0{ }^{\circ} \mathrm{C}$ and water (16 $\mathrm{mL}), 15 \%$ aq. $\mathrm{NaOH}(16 \mathrm{~mL})$, and water again $(50 \mathrm{~mL})$ were sequentially added with care and with 20-30 minutes of stirring between each addition. The white suspension was treated with $\mathrm{MgSO}_{4}$, filtered, and concentrated to give a viscous yellow oil. Purification by flash chromatography $\left(\mathrm{SiO}_{2}, 20 \rightarrow 30 \%\right.$ EtOAc/hexanes, $200 \mathrm{~mL}$ fractions) on the crude product afforded $17.1 \mathrm{mg}(65 \%)$ of triol $\mathbf{2 . 1 5}$ as a colorless viscous oil. TLC: $\mathrm{R}_{\mathrm{f}}=0.26\left(5 \% \mathrm{MeOH} / \mathrm{CH}_{2} \mathrm{Cl}_{2}\right)$; IR (film) 3351, 2933, 1612, 1514, 1248, $1033 \mathrm{~cm}^{-1} ;{ }^{1} \mathrm{H}$ NMR (400 MHz, $\left.\mathrm{CDCl}_{3}\right) \delta 7.28(\mathrm{~d}, J=8.6 \mathrm{~Hz}, 2 \mathrm{H}), 6.88(\mathrm{~d}, J=8.6$ $\mathrm{Hz}, 2 \mathrm{H}), 4.61(\mathrm{~d}, J=11.4 \mathrm{~Hz}, 1 \mathrm{H}), 4.39(\mathrm{~d}, J=11.4 \mathrm{~Hz}, 1 \mathrm{H}), 4.23(\mathrm{~d}, J=11.6 \mathrm{~Hz}, 1$ H), $4.14(\mathrm{~d}, J=12.0 \mathrm{~Hz}, 1 \mathrm{H}), 4.06(\mathrm{~d}, J=12.0 \mathrm{~Hz}, 1 \mathrm{H}), 3.96(\mathrm{~d}, J=11.6 \mathrm{~Hz}, 1 \mathrm{H}), 3.84$ (m, $1 \mathrm{H}), 3.79$ (s, $3 \mathrm{H}), 3.68$ (m $1 \mathrm{H}), 3.58$ (br m, $4 \mathrm{H}), 1.94(\mathrm{~m}, 3 \mathrm{H}), 1,65$ (m, $1 \mathrm{H}), 1.52$ $(\mathrm{m}, 1 \mathrm{H}), 1.16(\mathrm{~m}, 1 \mathrm{H}), 0.96(\mathrm{~s}, 3 \mathrm{H}) ;{ }^{13} \mathrm{C} \mathrm{NMR}\left(100 \mathrm{MHz}, \mathrm{CDCl}_{3}\right) \delta 159.3,147.2$, $137.2,130.1,129.7,113.9,74.2,70.7,62.4,58.6,57.8,55.2,42.1,36.6,28.9,26.3,22.8$; HRMS (EI) calculated for $\left[\mathrm{M}-\mathrm{H}_{2} \mathrm{O}\right]^{+} 318.1831$, found 318.1841.
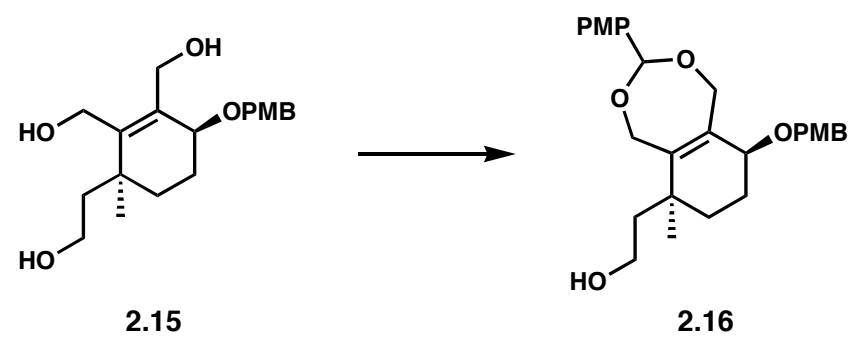
Alcohol 2.16 (From Organic Letters 2002, 4, 2063-2066): Triol 2.15 (17.0 g, 50.5 mmol) was placed in a $250 \mathrm{~mL}$ flask and dissolved in $100 \mathrm{~mL}$ dry $\mathrm{CH}_{2} \mathrm{Cl}_{2}$. Anisaldehyde dimethyl acetal $(11.0 \mathrm{~g}, 10.3 \mathrm{~mL}, 60.6 \mathrm{mmol})$ and pyridinium $p$-toluenesulfonic acid $(1.27 \mathrm{~g}, 5.1 \mathrm{mmol})$ were added. After $19 \mathrm{~h}$, triethylamine $(0.87 \mathrm{~g}, 1.2 \mathrm{~mL}, 8.6 \mathrm{mmol})$ was added and the volatiles were removed in vacuo. Purification by flash chromatography $\left(\mathrm{SiO}_{2}, 40 \rightarrow 50 \%\right.$ EtOAc/hexanes) on the crude product afforded $18.3 \mathrm{~g}(80 \%)$ of a $1: 1$ mixture of alcohols $\mathbf{2 . 1 6}$ as a colorless viscous oil. The diastereoisomers could be separated for analytical purposes, but were found to interconvert to a 1:1 mixture of diastereoisomers and some anisaldehyde when kept at $\mathrm{rt}$ for $24 \mathrm{~h}$. Thus, the purified mixture of diastereoisomers was generally used shortly after purification. 2.16a: TLC: $\mathrm{R}_{\mathrm{f}}=0.32(50 \%$ EtOAc/hexanes $) ;{ }^{1} \mathrm{H} \mathrm{NMR}\left(250 \mathrm{MHz}, \mathrm{CDCl}_{3}\right) \delta 7.42(\mathrm{~d}, J=8.4 \mathrm{~Hz}, 2 \mathrm{H})$, $7.26(\mathrm{~d}, J=8.8 \mathrm{~Hz}, 2 \mathrm{H}), 6.88(\mathrm{~d}, J=8.8 \mathrm{~Hz}, 2 \mathrm{H}), 6.86(\mathrm{~d}, J=8.8 \mathrm{~Hz} ; 2 \mathrm{H}), 5.75(\mathrm{~s}, 1$ H), 4.64-4.29 (m, 4 H), 4.20-4.05 (m, 2 H), 3.81 (s, 3 H), 3.80 (s, 3 H), 3.70-3.61 (m, 3 H), 2.0-1.85 (m, $2 \mathrm{H}), 1.70-1.60(\mathrm{~m}, 2 \mathrm{H}), 1.50(\mathrm{~m}, 1 \mathrm{H}), 1.26(\mathrm{~m}, 1 \mathrm{H}), 1.07(\mathrm{~s}, 3 \mathrm{H})$; HRMS (EI) calculated for $[\mathrm{M}]^{+} 454.2355$, found 454.2342. 2.16b: TLC: $\mathrm{R}_{\mathrm{f}}=0.24(50 \%$ EtOAc/hexanes); ${ }^{1} \mathrm{H}$ NMR $\left(250 \mathrm{MHz}, \mathrm{CDCl}_{3}\right) \delta 7.41(\mathrm{~d}, J=8.8 \mathrm{~Hz}, 2 \mathrm{H}), 7.25(\mathrm{~d}, J=8.8$ $\mathrm{Hz}, 2 \mathrm{H}), 6.88(\mathrm{~d}, J=8.8 \mathrm{~Hz}, 2 \mathrm{H}), 6.87(\mathrm{~d}, J=8.8 \mathrm{~Hz}, 2 \mathrm{H}), 5.76(\mathrm{~s}, 1 \mathrm{H}), 4.56(\mathrm{~d}, J=$ $11.4 \mathrm{~Hz}, 1 \mathrm{H}), 4.43-4.17(\mathrm{~m}, 4 \mathrm{H}), 4.32(\mathrm{~d}, J=11.4 \mathrm{~Hz}, 1 \mathrm{H}), 3.810(\mathrm{~s}, 3 \mathrm{H}), 3.805$ (s, 3 H), $3.71(\mathrm{~m}, 3 \mathrm{H}), 1.95-1.60(\mathrm{~m}, 5 \mathrm{H}), 1.26(\mathrm{~m}, 1 \mathrm{H}), 1.02$ (s, $3 \mathrm{H})$; HRMS (EI) calculated for $[\mathrm{M}]^{+} 454.2355$, found 454.2330 . 


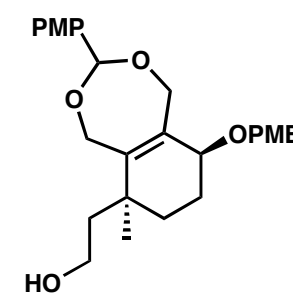

2.16

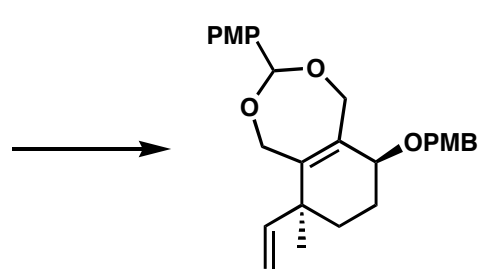

2.17

Alkene 2.17 (From Organic Letters 2002, 4, 2063-2066): Alcohol 2.16 (4.43 g, 9.8 mmol) was placed in a $100 \mathrm{~mL}$ flask and dissolved in $35 \mathrm{~mL}$ dry THF. The solution was treated with $o$-nitrophenylselenocyanate $(2.66 \mathrm{~g}, 11.7 \mathrm{mmol})$ and cooled to $0{ }^{\circ} \mathrm{C}$. Tri- $n$ butylphosphine $(2.37 \mathrm{~g}, 2.92 \mathrm{~mL}, 11.7 \mathrm{mmol})$ was added dropwise and the mixture was stirred for $1 \mathrm{~h}$, then warmed to rt. Complete selenide formation was confirmed by TLC in $50 \% \mathrm{EtOAc} /$ hexanes. The mixture was again cooled to $0{ }^{\circ} \mathrm{C}$, then treated with $30 \%$ aq. $\mathrm{H}_{2} \mathrm{O}_{2}$ (1.9 mL, $\left.13 \mathrm{mmol}\right)$. After $2 \mathrm{~h}$ and warming to $\mathrm{rt}$, the reaction was heated to $45^{\circ} \mathrm{C}$ and diisopropylethylamine $(2.59 \mathrm{~g}, 3.48 \mathrm{~mL}, 20 \mathrm{mmol})$ was added. After $1 \mathrm{~h}$ more, the reaction was cooled to $\mathrm{rt}$ and diluted with $\mathrm{CH}_{2} \mathrm{Cl}_{2}$ and $\mathrm{H}_{2} \mathrm{O}$. The mixture was extracted with $\mathrm{CH}_{2} \mathrm{Cl}_{2}(3 \mathrm{x})$, dried over $\mathrm{MgSO}_{4}$, and concentrated. Purification by flash chromatography $\left(\mathrm{SiO}_{2}, 10 \rightarrow 20 \% \mathrm{EtOAc/hexanes}\right)$ on the crude product afforded $3.05 \mathrm{~g}$ (71\%) of a 1:1 mixture of alkenes $\mathbf{2 . 1 7}$ as a yellow viscous oil. The diastereoisomers could be separated by careful chromatography, but were found to quickly interconvert to a 1:1 mixture of diastereoisomers and some anisaldehyde. Thus, the purified mixture of diastereoisomers was generally used shortly after purification. 2.17a: $T L C: R_{f}=0.34$ (20\% EtOAc/hexanes). 2.17b: $R_{\mathrm{f}}=0.29$ (20\% EtOAc/hexanes). Mixture: HRMS (EI) calculated for $[\mathrm{M}-\mathrm{PMB}]^{+}$315.1596, found 315.1591. 


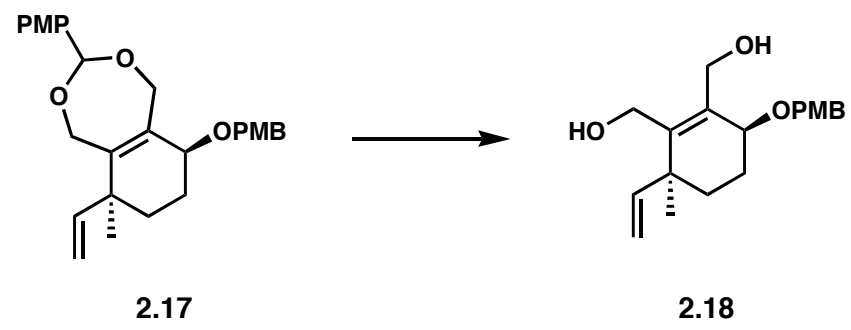

Diol 2.18 (From Organic Letters 2002, 4, 2063-2066): Acetal 2.17 (5.43 g, 12.4 mmol) was placed in a $500 \mathrm{~mL}$ flask and dissolved in $260 \mathrm{~mL} \mathrm{MeOH}$. To the solution was added pyridinium $p$-toluenesulfonic acid $(0.82 \mathrm{~g}, 3.25 \mathrm{mmol})$. After $2 \mathrm{~h}$, the reaction was quenched with saturated aq. $\mathrm{NaHCO}_{3}$ and the mixture was extracted with $\mathrm{CH}_{2} \mathrm{Cl}_{2}(3 \mathrm{x})$. Extracts were washed with brine, dried over $\mathrm{MgSO}_{4}$, and concentrated. Purification by flash chromatography $\left(\mathrm{SiO}_{2}, 50 \rightarrow 60 \%\right.$ EtOAc/hexanes) on the crude product afforded $3.25 \mathrm{~g}(82 \%)$ of diol $\mathbf{2 . 1 8}$ as a colorless viscous oil. TLC: $\mathrm{R}_{\mathrm{f}}=0.27(50 \%$ EtOAc/hexanes); IR (film) 3369, 2934, 1612, 1514, 1248, 1034, 998, $823 \mathrm{~cm}^{-1}$; ${ }^{1} \mathrm{H}$ NMR $\left(400 \mathrm{MHz}, \mathrm{CDCl}_{3}\right) \delta 7.28(\mathrm{~d}, J=8.8 \mathrm{~Hz}, 2 \mathrm{H}), 6.89(\mathrm{~d}, J=8.8 \mathrm{~Hz}, 2 \mathrm{H}), 5.77(\mathrm{dd}, J=$ 10.6, 17.6 Hz, $1 \mathrm{H}), 5.10(\mathrm{dd}, J=1.2,10.8 \mathrm{~Hz}, 1 \mathrm{H}), 5.03(\mathrm{dd}, J=1.2,17.6 \mathrm{~Hz}, 1 \mathrm{H})$, $4.62(\mathrm{~d}, J=11.2 \mathrm{~Hz}, 1 \mathrm{H}), 4.41(\mathrm{~d}, J=11.2 \mathrm{~Hz}, 1 \mathrm{H}), 4.23(\mathrm{~d}, J=11.6 \mathrm{~Hz}, 1 \mathrm{H}), 4.13(\mathrm{~d}$, $J=11.6 \mathrm{~Hz}, 1 \mathrm{H}), 4.09(\mathrm{~s}, 1 \mathrm{H}), 4.08(\mathrm{~s}, 1 \mathrm{H}), 4.01(\operatorname{app} \mathrm{t}, J=5.4 \mathrm{~Hz}, 1 \mathrm{H}), 3.80(\mathrm{~s}, 3 \mathrm{H})$, 2.70 (br s, $2 \mathrm{H}), 1.83(\mathrm{~m}, 2 \mathrm{H}), 1.72(\mathrm{~m}, 1 \mathrm{H}), 1.36$ (m, $1 \mathrm{H}), 1.14$ (s, $3 \mathrm{H}) ;{ }^{13} \mathrm{C}$ NMR (100 $\left.\mathrm{MHz}, \mathrm{CDCl}_{3}\right) \delta 159.3,145.2,144.8,137.8,130.3,129.6,113.9,113.9,75.5,70.7,61.6$, 59.5, 55.3, 41.9, 32.9, 23.5, 23.4; HRMS (EI) calculated for $\left[\mathrm{M}-\mathrm{H}_{2} \mathrm{O}\right]^{+} 300.1725$, found 300.1718. 


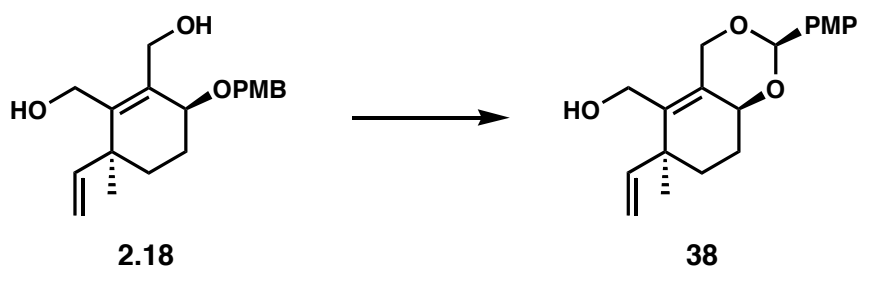

Allylic alcohol 38 (From Organic Letters 2002, 4, 2063-2066): To diol 2.18 (3.25 g, $10.2 \mathrm{mmol})$ in $100 \mathrm{~mL}$ dry $\mathrm{CH}_{2} \mathrm{Cl}_{2}$ was added DDQ (2.32 g, $\left.10.2 \mathrm{mmol}\right)$ and the mixture was stirred under argon for 30 min. Precipitated $\mathrm{DDQH}_{2}$ was removed by filtration, and the filtrate was washed with saturated aqueous $\mathrm{NaHCO}_{3}(100 \mathrm{~mL})$, brine, dried over $\mathrm{MgSO}_{4}$, and concentrated. The crude product was purified by flash chromatography $\left(\mathrm{SiO}_{2}, 30 \rightarrow 55 \%\right.$ EtOAc/hexanes) to afford $2.21 \mathrm{~g}(69 \%)$ of white solid allylic alcohol 38 as a single diastereoisomer and $300 \mathrm{mg}(9 \%)$ of starting material. $\mathrm{mp}=145^{\circ} \mathrm{C}$; TLC: $\mathrm{R}_{\mathrm{f}}=0.33$ (50\% EtOAc/hexanes); IR (film) 3435, 2937, 2836, 1615, 1518, 1250, 1094, 1033, $998 \mathrm{~cm}^{-1} ;{ }^{1} \mathrm{H}$ NMR $\left(500 \mathrm{MHz}, \mathrm{CDCl}_{3}\right) \delta 7.43(\mathrm{~d}, J=6.8 \mathrm{~Hz}, 2 \mathrm{H}), 6.89(\mathrm{~d}, J=6.8$ $\mathrm{Hz}, 2 \mathrm{H}), 5.75(\mathrm{dd}, J=17.3,10.6 \mathrm{~Hz}, 1 \mathrm{H}), 5.65(\mathrm{~s}, 1 \mathrm{H}), 5.09$ (dd, $J=10.6,1.2 \mathrm{~Hz}, 1 \mathrm{H})$, $5.04(\mathrm{~d}, J=13.8 \mathrm{~Hz}, 1 \mathrm{H}), 4.93(\mathrm{dd}, J=17.3,1.2 \mathrm{~Hz}, 1 \mathrm{H}), 4.46(\mathrm{dd}, J=9.8,6.3 \mathrm{~Hz}, 1 \mathrm{H})$, $4.41(\mathrm{~d}, J=13.8 \mathrm{~Hz}, 1 \mathrm{H}), 4.24(\mathrm{~d}, J=11.7 \mathrm{~Hz}, 1 \mathrm{H}), 3.96(\mathrm{~d}, 11.7 \mathrm{~Hz}, 1 \mathrm{H}), 3.79(\mathrm{~s}, 3 \mathrm{H})$, $1.94(\mathrm{~m}, 1 \mathrm{H}), 1.80(\mathrm{~m}, 1 \mathrm{H}), 1.62(\mathrm{~m}, 1 \mathrm{H}), 1.52(\mathrm{~m}, 1 \mathrm{H}), 1.23(\mathrm{~s}, 3 \mathrm{H}) ;{ }^{13} \mathrm{C}$ NMR $(150$ $\left.\mathrm{MHz}, \mathrm{CDCl}_{3}\right) \delta 160.1,144.5,136.3,133.4,130.9,127.6,114.4,113.8,100.8,75.4,66.8$, $58.5,55.4,42.1,34.5,26.0,24.9$; HRMS (MALDI-FTMS) calculated for $[\mathrm{M}+\mathrm{Na}]^{+}$ 339.1567, found 339.1574.

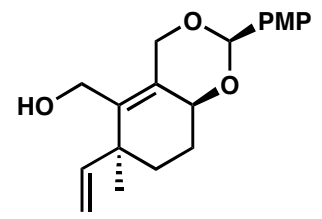

2.19

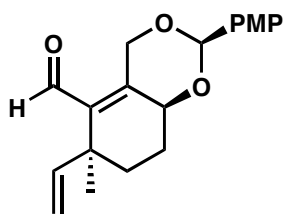

2.20 
Aldehyde 2.20 (From Organic Letters 2002, 4, 2063-2066): Allylic alcohol 2.19 (325 $\mathrm{mg}, 1.03 \mathrm{mmol}$ ) was dissolved in $10 \mathrm{~mL}$ dry $\mathrm{CH}_{2} \mathrm{Cl}_{2}$ and cooled to $0{ }^{\circ} \mathrm{C}$. Dess-Martin periodinane $(523 \mathrm{mg}, 1.23 \mathrm{mmol}$ ) was added and the mixture was stirred under argon for 20 min. The reaction was then diluted with $\mathrm{Et}_{2} \mathrm{O}(20 \mathrm{~mL})$ and $1 \mathrm{M} \mathrm{NaOH}(15 \mathrm{~mL})$ was added. Shortly, the phases became homogeneous and were extracted with $\mathrm{Et}_{2} \mathrm{O}(3 \times 20$ $\mathrm{mL}$ ). Combined organic extracts were washed with brine, dried over $\mathrm{MgSO}_{4}$, and concentrated to afford $322 \mathrm{mg}$ of aldehyde $\mathbf{2 . 2 0}(100 \%)$ as a very pale yellow oil that was used without further purification. TLC: $\mathrm{R}_{\mathrm{f}}=0.56$ (40\% EtOAc/hexanes); IR (film) 2937, 2838, 1691, 1615, 1517, 1250, 1097, 1032, $831 \mathrm{~cm}^{-1} ;{ }^{1} \mathrm{H}$ NMR (500 MHz, $\left.\mathrm{CDCl}_{3}\right)$ $\delta 9.69(\mathrm{~s}, 1 \mathrm{H}), 7.42(\mathrm{~d}, J=8.8 \mathrm{~Hz}, 2 \mathrm{H}), 6.89(\mathrm{~d}, J=8.8 \mathrm{~Hz}, 2 \mathrm{H}), 5.94(\mathrm{dd}, J=17.1,10.4$ Hz, 1H), $5.72(\mathrm{~s}, 1 \mathrm{H}), 5.38$ (d, $J=15.4 \mathrm{~Hz}, 1 \mathrm{H}), 5.25$ (app d, $J=10.4 \mathrm{~Hz}, 1 \mathrm{H}), 5.09$ (app d, $J=17.1 \mathrm{~Hz}, 1 \mathrm{H}), 4.57(\mathrm{~d}, J=15.4 \mathrm{~Hz}, 1 \mathrm{H}), 4.54(\operatorname{app~t}, 1 \mathrm{H}), 3.80(\mathrm{~s}, 3 \mathrm{H}), 1.96(\mathrm{~m}$, 1H), $1.85(\mathrm{~m}, 1 \mathrm{H}), 1.67(\mathrm{~m}, 1 \mathrm{H}), 1.55(\mathrm{~m}, 1 \mathrm{H}), 1.27(\mathrm{~s}, 3 \mathrm{H}) ;{ }^{13} \mathrm{C} \mathrm{NMR}\left(125 \mathrm{MHz}, \mathrm{CDCl}_{3}\right)$ ઈ 194.2, 160.2, 144.2, 144.2, 135.9, 130.4, 127.5, 115.7, 113.8, 100.5, 74.9, 66.2, 55.4, 40.0, 34.6, 26.4, 24.5; HRMS (MALDI-FTMS) calculated for [M+Na $]^{+} 337.1410$, found 337.1409 .

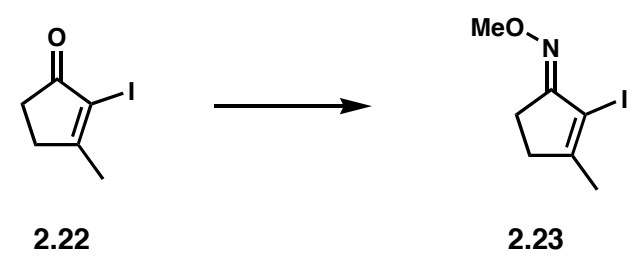

Oxime 2.23 (From Organic Letters 2002, 4, 2063-2066): Iodoenone 2.22 (488 mg, 2.2 mmol) was placed in a $15-\mathrm{mL}$ flask and dissolved in $2.2 \mathrm{~mL}$ dry $\mathrm{MeOH}$. $O$ methylhydroxylamine hydrochloride (294 mg, $3.5 \mathrm{mmol}$ ) was added, followed by 
pyridine (382 $\mathrm{mg}, 0.39 \mathrm{~mL}, 4.8 \mathrm{mmol}$ ), and the mixture was stirred for $14 \mathrm{~h}$. The reaction was quenched with saturated aq. $\mathrm{NH}_{4} \mathrm{Cl}$ and extracted with $\mathrm{CH}_{2} \mathrm{Cl}_{2}$ (3x). Extracts were washed with brine, dried over $\mathrm{MgSO}_{4}$, and concentrated. Purification of the crude product by flash chromatography $\left(\mathrm{SiO}_{2}, 3 \%\right.$ EtOAc/hexanes) afforded $458 \mathrm{mg}$ $(83 \%)$ of oxime $\mathbf{2 . 2 3}$ as a white solid. TLC: $\mathrm{R}_{\mathrm{f}}=0.67$ (30\% EtOAc/hexanes); ${ }^{1} \mathrm{H}$ NMR $\left(400 \mathrm{MHz}, \mathrm{CDCl}_{3}\right) \delta 3.93$ (s, 3H), 2.72 (m, 2H), 2.58 (m, 2H), 2.03 (app t, 3H); ${ }^{13} \mathrm{C}$ NMR $\left(100 \mathrm{MHz}, \mathrm{CDCl}_{3}\right) \delta 165.1,161.6,89.9,62.2,35.4,25.5,20.2$.

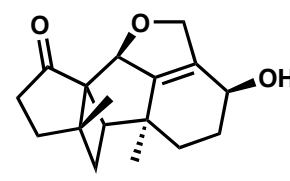

12

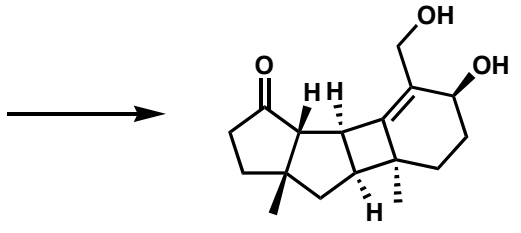

16

Tetracycle 16 (From Organic Letters 2002, 4, 2063-2066): To cyclobutyl ketone 12 (4.3 $\mathrm{mg}, 0.016 \mathrm{mmol})$ was added a $0.3 \mathrm{M}$ THF solution of $\mathrm{SmI}_{2}(0.147 \mathrm{~mL}, 0.044 \mathrm{mmol})$. The solution remained blue while stirring under argon for about $1 \mathrm{~min}$, then it faded to yellow. The reaction was then quenched with $0.1 \mathrm{~N} \mathrm{HCl}(0.2 \mathrm{~mL})$, taken up in $\mathrm{Et}_{2} \mathrm{O}$, and washed successively with water and brine. The washes were extracted with $\mathrm{Et}_{2} \mathrm{O}(2 \times 1$ $\mathrm{mL}$ ), and the combined organic layers were dried over $\mathrm{MgSO}_{4}$ and concentrated. Purification of the crude product by flash chromatography $\left(\mathrm{SiO}_{2}, 40 \rightarrow 60 \%\right.$ EtOAc/hexanes) afforded $1.0 \mathrm{mg}(23 \%)$ of tetracycle $\mathbf{1 6}$ as a colorless oil. TLC: $\mathbf{R}_{\mathrm{f}}=$ 0.15 (50\% EtOAc/hexanes); IR (film) 3415, 2926, 2857, 1738, 1452, 1409, 1383, 990 $\mathrm{cm}^{-1} ;{ }^{1} \mathrm{H}$ NMR $\left(500 \mathrm{MHz}, \mathrm{CDCl}_{3}\right) \delta 4.38(\mathrm{~d}, J=11.0 \mathrm{~Hz}, 1 \mathrm{H}), 4.25(\mathrm{~m}, 1 \mathrm{H}), 4.11(\mathrm{~d}, J=$ $11.0 \mathrm{~Hz}, 1 \mathrm{H}), 3.69$ (d, $J=7.4 \mathrm{~Hz}, 1 \mathrm{H}), 2.64(\mathrm{~m}, 1 \mathrm{H}), 2.57(\mathrm{br}, 1 \mathrm{H}), 2.36(\mathrm{~m}, 1 \mathrm{H}), 2.26$ $(\mathrm{m}, 1 \mathrm{H}), 1.92(\mathrm{~m}, 1 \mathrm{H}), 1.82-1.68(\mathrm{~m}, 5 \mathrm{H}), 1.31(\mathrm{~s}, 3 \mathrm{H}), 1.22(\mathrm{~s}, 3 \mathrm{H}) ;{ }^{13} \mathrm{C}$ NMR $(125$ 
$\left.\mathrm{MHz}, \mathrm{CDCl}_{3}\right) \delta 222.4,149.7,127.4,67.7,62.9,61.4,54.2,53.8,49.4,42.7,39.0,38.2$, 33.9, 29.1, 27.0, 25.2, 24.3; HRMS (MALDI-FTMS) calculated for $[\mathrm{M}+\mathrm{Na}]^{+}$299.1617, found 299.1623 .

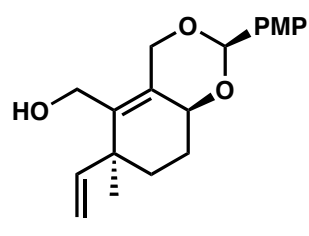

38

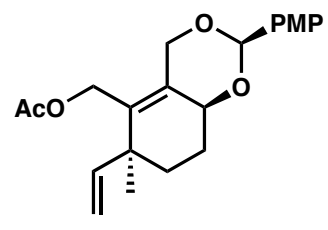

41

Allylic acetate 41 (Step b, Scheme 11): Allylic alcohol 38 (434 mg, 1.37 mmol) was dissolved in $10 \mathrm{~mL}$ dry pyridine. Acetic anhydride $(0.26 \mathrm{~mL}, 2.74 \mathrm{mmol})$ and a catalytic amount of DMAP ( $\sim 5 \mathrm{mg})$ were added. The reaction was stirred under argon for $15 \mathrm{~min}$. Saturated aqueous $\mathrm{NH}_{4} \mathrm{Cl}(10 \mathrm{~mL})$ was added, and the mixture was extracted with $\mathrm{CH}_{2} \mathrm{Cl}_{2}$ ( 3 x $10 \mathrm{~mL}$ ). Combined organic extracts were washed with brine, dried over $\mathrm{MgSO}_{4}$, and concentrated. The crude product was filtered through a short pad of silica gel with $\mathrm{Et}_{2} \mathrm{O}$, giving $490 \mathrm{mg}(100 \%)$ of allylic acetate $\mathbf{4 1}$ as a nearly colorless oil. TLC: $\mathrm{R}_{\mathrm{f}}=0.60$ (50\% EtOAc/hexanes); IR (film) 2938, 2836, 1738, 1616, 1518, 1368, 1249, 1096, 1027 , $830 \mathrm{~cm}^{-1} ;{ }^{1} \mathrm{H}$ NMR $\left(500 \mathrm{MHz}, \mathrm{CDCl}_{3}\right) \delta 7.42(\mathrm{~d}, J=8.8 \mathrm{~Hz}, 2 \mathrm{H}), 6.89(\mathrm{~d}, J=8.8 \mathrm{~Hz}$, 2H), $5.73(\mathrm{dd}, J=17.5,10.3 \mathrm{~Hz}, 1 \mathrm{H}), 5.65(\mathrm{~s}, 1 \mathrm{H}), 5.10(\mathrm{dd}, J=10.3,1.1 \mathrm{~Hz}, 1 \mathrm{H}), 4.93$ $(\mathrm{dd}, J=17.5,1.1 \mathrm{~Hz}, 1 \mathrm{H}), 4.87(\mathrm{~d}, J=14.0 \mathrm{~Hz}, 1 \mathrm{H}), 4.64(\mathrm{~d}, J=12.3 \mathrm{~Hz}, 1 \mathrm{H}), 4.47(\mathrm{dd}$, 1H), $4.40(\mathrm{~d}, J=12.3 \mathrm{~Hz}, 1 \mathrm{H}), 4.37$ (d, $J=14.0 \mathrm{~Hz}, 1 \mathrm{H}), 3.80(\mathrm{~s}, 3 \mathrm{H}), 2.03$ (s, 3H), 1.94 $(\mathrm{m}, 1 \mathrm{H}), 1.82(\mathrm{~m}, 1 \mathrm{H}), 1.63(\mathrm{~m}, 1 \mathrm{H}), 1.54(\mathrm{~m}, 1 \mathrm{H}), 1.13(\mathrm{~s}, 3 \mathrm{H}) ;{ }^{13} \mathrm{C}$ NMR $(125 \mathrm{MHz}$ $\left.\mathrm{CDCl}_{3}\right) \delta 170.8,160.1,143.9,135.5,131.7,130.8,127.6,114.7,113.8,100.8,75.4,66.6$ 60.0, 55.4, 42.3, 34.4, 25.8, 24.9, 21.1; HRMS (MALDI-FTMS) calculated for [M+Na] ${ }^{+}$ 381.1672, found 381.1680 . 


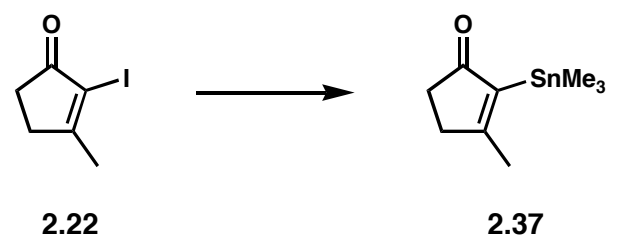

Vinylstannane 2.37 (From Organic Letters 2002, 4, 2063-2066): Iodoenone 2.22 (444 $\mathrm{mg}, 2.0 \mathrm{mmol})$ was dissolved in $10 \mathrm{~mL}$ dry benzene. Hexamethylditin $(1.19 \mathrm{~mL}, 4.0$ mmol $)$ was added, followed by $\mathrm{Pd}\left(\mathrm{PPh}_{3}\right)_{4}(116 \mathrm{mg}, 0.10 \mathrm{mmol})$. The resulting mixture was degassed by bubbling argon through the solution for $15 \mathrm{~min}$, then it was immersed in an oil bath at $80{ }^{\circ} \mathrm{C}$ and stirred under argon. After 3 days, the mixture turned black, and TLC indicated near completion of the reaction. The reaction was cooled to room temperature and transferred to a separatory funnel with pentane $(40 \mathrm{~mL})$, then washed with saturated aqueous $\mathrm{KF}(3 \times 20 \mathrm{~mL})$ and $\mathrm{H}_{2} \mathrm{O}(2 \times 20 \mathrm{~mL})$. The organic layer was dried over $\mathrm{MgSO}_{4}$ and solvent was carefully removed, as the product stannane $\mathbf{2 . 3 7}$ is somewhat volatile. The crude product was purified by flash chromatography $\left(\mathrm{SiO}_{2}, 10\right.$ $\rightarrow 20 \% \mathrm{Et}_{2} \mathrm{O} /$ pentane) to afford $464 \mathrm{mg}(90 \%)$ of stannane $\mathbf{2 . 3 7}$ as a pale yellow oil and $18 \mathrm{mg}(4 \%)$ of recovered iodoenone 2.22. TLC: $\mathrm{R}_{\mathrm{f}}=0.60$ (50\% EtOAc/hexanes); IR (film) 2918, 2850, 1685, 1594, 1256, 1146, 774, $530 \mathrm{~cm}^{-1}$; ${ }^{1} \mathrm{H}$ NMR (500 MHz, $\left.\mathrm{CDCl}_{3}\right) \delta$ $2.62(\mathrm{dt}, 2 \mathrm{H}), 2.35(\mathrm{dt}, 2 \mathrm{H}), 2.13(\mathrm{~s}, 3 \mathrm{H}), 0.24(\mathrm{~s}, 9 \mathrm{H}) ;{ }^{13} \mathrm{C} \mathrm{NMR}\left(125 \mathrm{MHz}, \mathrm{CDCl}_{3}\right) \delta$ 215.1, 186.4, 142.7, 36.1, 35.8, 21.1, -8.9; HRMS (MALDI-FTMS) calculated for $[\mathrm{M}+\mathrm{H}]^{+}$261.0296, found 261.0302 . 


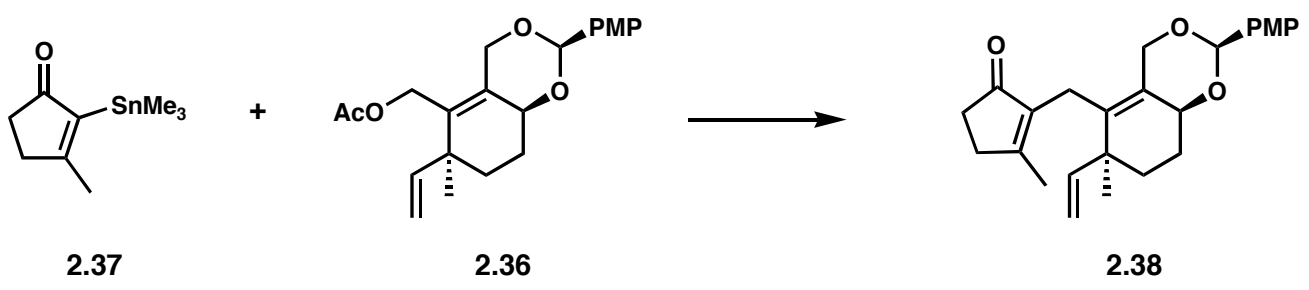

Stille product 2.38 (From Organic Letters 2002, 4, 2063-2066): LiCl (51 mg, 1.2 mmol) was flame-dried in a 5-mL round-bottom flask. After cooling, $\mathrm{Pd}_{2} \mathrm{dba}_{3}(55 \mathrm{mg}$, $0.06 \mathrm{mmol}$ ) was added under argon. A solution of allylic acetate $\mathbf{2 . 3 6}$ (102 $\mathrm{mg}, 0.30$ mmol) in $0.5 \mathrm{~mL} N$-methyl-2-pyrrolidinone (NMP) was then added, followed by a 0.2 $\mathrm{mL}$ NMP rinse. The solution was stirred $10 \mathrm{~min}$ at room temperature, then a solution of stannane 2.37 (77 mg, $0.30 \mathrm{mmol}$ ) in $0.5 \mathrm{~mL}$ NMP was added, followed by a $0.2 \mathrm{~mL}$ NMP rinse. The solution was warmed in a $50{ }^{\circ} \mathrm{C}$ oil bath for $16 \mathrm{~h}$, then cooled to room temperature. The reaction was extracted from $10 \mathrm{~mL}$ water with $\mathrm{Et}_{2} \mathrm{O}(3 \times 5 \mathrm{~mL})$, dried over $\mathrm{MgSO}_{4}$, and concentrated. Purification by flash chromatography $(20 \rightarrow 30 \%$ EtOAc/hexanes) afforded $98 \mathrm{mg}(87 \%)$ of Stille product $\mathbf{2 . 3 8}$ as a colorless oil. TLC: $\mathbf{R}_{\mathrm{f}}$ $=0.40$ (50\% EtOAc/hexanes); IR (film) 2924, 2852, 1698, 1641, 1616, 1517, 1249, 1095, $1033 \mathrm{~cm}^{-1} ;{ }^{1} \mathrm{H}$ NMR $\left(400 \mathrm{MHz}, \mathrm{CDCl}_{3}\right) \delta 7.41(\mathrm{~d}, J=8.8 \mathrm{~Hz}, 2 \mathrm{H}), 6.87(\mathrm{~d}, J=8.8 \mathrm{~Hz}$, 2H), $5.80(\mathrm{dd}, J=17.3,10.6 \mathrm{~Hz}, 1 \mathrm{H}), 5.62(\mathrm{~s}, 1 \mathrm{H}), 5.03(\mathrm{dd}, J=10.6,0.8 \mathrm{~Hz}, 1 \mathrm{H}), 4.98$ $(\mathrm{dd}, J=17.3,0.8 \mathrm{~Hz}, 1 \mathrm{H}), 4.83(\mathrm{~d}, J=13.5 \mathrm{~Hz}, 1 \mathrm{H}), 4.44(\mathrm{dd}, 1 \mathrm{H}), 4.27(\mathrm{~d}, J=13.5 \mathrm{~Hz}$, 1H), 3.77 (s, 3H), 3.07 (d, $J=16.8 \mathrm{~Hz}, 1 \mathrm{H}), 2.87$ (d, $J=16.8 \mathrm{~Hz}, 1 \mathrm{H}), 2.42(\mathrm{br}, 2 \mathrm{H}), 2.29$ $(\mathrm{m}, 2 \mathrm{H}), 2.07(\mathrm{~s}, 3 \mathrm{H}), 1.93(\mathrm{~m}, 1 \mathrm{H}), 1.85(\mathrm{~m}, 1 \mathrm{H}), 1.55(\mathrm{~m}, 2 \mathrm{H}), 1.05(\mathrm{~s}, 3 \mathrm{H}) ;{ }^{13} \mathrm{C}$ NMR $\left(125 \mathrm{MHz}, \mathrm{CDCl}_{3}\right) \delta 208.9,170.3,160.0,144.6,138.1,133.9,131.1,129.4,127.5,113.7$, $113.2,100.9,75.7,68.0,55.3,42.6,35.1,33.9,32.1,25.3,25.0,23.6,17.8$; HRMS (MALDI-FTMS) calculated for $[\mathrm{M}+\mathrm{Na}]^{+}$417.2036, found 417.2034. 


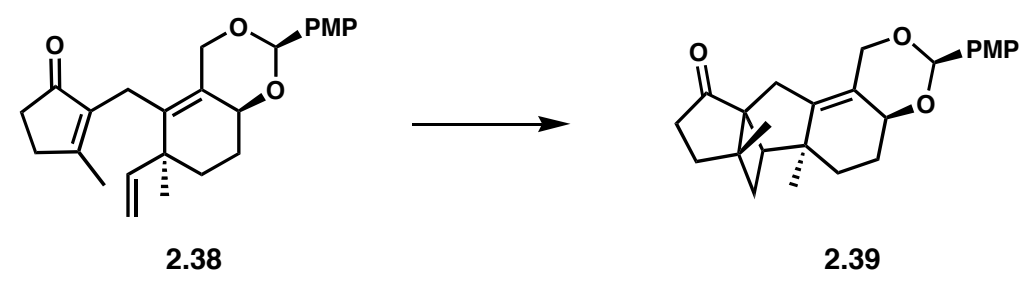

Cyclobutane 2.39 (From Organic Letters 2002, 4, 2063-2066): To Stille product 2.38 $(100 \mathrm{mg}, 0.25 \mathrm{mmol})$ in $5.0 \mathrm{~mL} \mathrm{Et}_{2} \mathrm{O}$ in a quartz test tube was added diisopropylethylamine (11 $\mu \mathrm{L}, 0.063 \mathrm{mmol})$, and the reaction was irradiated for $3 \mathrm{~h}$ with a $450 \mathrm{~W}$ Hanovia medium pressure mercury vapor lamp (no filter). The mixture was concentrated and purification by flash chromatography $\left(\mathrm{SiO}_{2}, 10 \rightarrow 20 \%\right.$ EtOAc/hexanes) afforded $76 \mathrm{mg}$ (76\%) of cyclobutane 2.39 as a white solid. TLC: $\mathrm{R}_{\mathrm{f}}=$ 0.50 (40\% EtOAc/hexanes); IR (film) 2953, 2859, 1724, 1615, 1518, 1302, 1249, 1073 $\mathrm{cm}^{-1} ;{ }^{1} \mathrm{H}$ NMR $\left(500 \mathrm{MHz}, \mathrm{CDCl}_{3}\right) \delta 7.50(\mathrm{~d}, J=8.7 \mathrm{~Hz}, 2 \mathrm{H}), 6.97(\mathrm{~d}, J=8.7 \mathrm{~Hz}, 2 \mathrm{H})$, $5.83(\mathrm{~s}, 1 \mathrm{H}), 4.80(\mathrm{~d}, J=12.0 \mathrm{~Hz}, 1 \mathrm{H}), 4.41(\mathrm{~d}, J=12.0 \mathrm{~Hz}, 1 \mathrm{H}), 4.32(\mathrm{br}, 1 \mathrm{H}), 3.87(\mathrm{~s}$, 3H), $2.79(\mathrm{~m}, 1 \mathrm{H}), 2.69(\mathrm{~d}, J=16.9 \mathrm{~Hz}, 1 \mathrm{H}), 2.57(\mathrm{~d}, J=16.9 \mathrm{~Hz}, 1 \mathrm{H}), 2.46(\mathrm{~m}, 2 \mathrm{H})$, $2.12(\mathrm{~m}, 2 \mathrm{H}), 1.97(\mathrm{~m}, 2 \mathrm{H}), 1.86(\mathrm{~m}, 1 \mathrm{H}), 1.73(\mathrm{~m}, 1 \mathrm{H}), 1.30(\mathrm{~m}, 2 \mathrm{H}), 1.13(\mathrm{~s}, 3 \mathrm{H}), 1.01$ (s, 3H); ${ }^{13} \mathrm{C}$ NMR $\left(125 \mathrm{MHz}, \mathrm{CDCl}_{3}\right) \delta 220.4,160.1,144.1,131.4,127.7,124.3,113.8$, $102.4,72.7,68.5,60.2,55.4,50.8,43.3,39.9,38.2,35.3,34.2,26.9,25.6,25.3,23.9$, 23.2; HRMS (MALDI-FTMS) calculated for $[\mathrm{M}+\mathrm{Na}]^{+}$417.2036, found 417.2043.

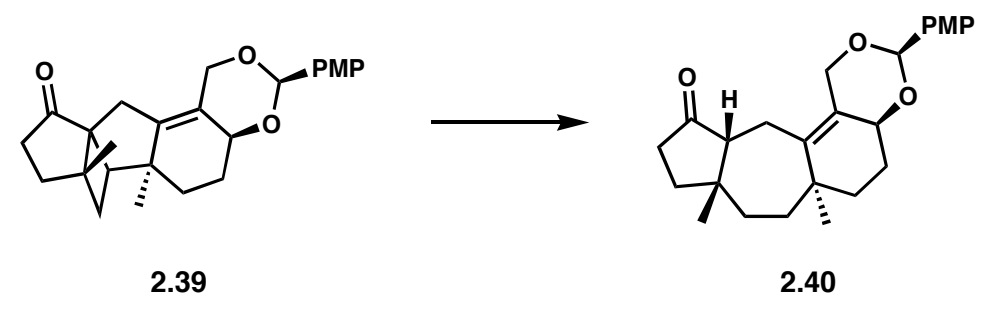

Ketone 2.40 (From Organic Letters 2002, 4, 2063-2066): To cyclobutane 2.39 (18.0 $\mathrm{mg}, 0.046 \mathrm{mmol}$ ) in $1.0 \mathrm{~mL}$ of degassed THF was added a 0.1 M THF solution of $\mathrm{SmI}_{2}$ 
(0.97 mL, $0.097 \mathrm{mmol})$, quickly followed by HMPA $(0.06 \mathrm{~mL})$. The solution remained purple while stirring under argon until it was quenched after 5 min with $\mathrm{pH}=7$ phosphate buffer $(2 \mathrm{~mL})$. The mixture was extracted with $\mathrm{CH}_{2} \mathrm{Cl}_{2}(3 \times 2 \mathrm{~mL})$, dried over $\mathrm{MgSO}_{4}$, and concentrated. Purification by flash chromatography $\left(\mathrm{SiO}_{2}, 10 \rightarrow 15 \%\right.$ EtOAc/hexanes) on the crude product afforded $13.0 \mathrm{mg}(72 \%)$ of ketone $\mathbf{2 . 4 0}$ as a colorless oil. TLC: $R_{\mathrm{f}}=0.37$ (25\% EtOAc/hexanes); IR (film) 2924, 2853, 1737, 1615, 1518, 1456, 1249, $1171 \mathrm{~cm}^{-1} ;{ }^{1} \mathrm{H}$ NMR $\left(500 \mathrm{MHz} \mathrm{CDCl}_{3}\right) \delta 7.40(\mathrm{~d}, J=8.8 \mathrm{~Hz}, 2 \mathrm{H})$, $6.88(\mathrm{~d}, J=8.8 \mathrm{~Hz}, 2 \mathrm{H}), 5.62(\mathrm{~s}, 1 \mathrm{H}), 4.84(\mathrm{~d}, J=12.7 \mathrm{~Hz}, 1 \mathrm{H}), 4.26(\mathrm{~d}, J=12.7 \mathrm{~Hz}$, 1H), 4.26 (br, 1H), $3.79(\mathrm{~s}, 3 \mathrm{H}), 2.33(\mathrm{~m}, 4 \mathrm{H}), 1.94(\mathrm{~m}, 6 \mathrm{H}), 1.66(\mathrm{~m}, 5 \mathrm{H}), 1.16(\mathrm{~s}, 3 \mathrm{H})$, $0.99(\mathrm{~s}, 3 \mathrm{H}) ;{ }^{13} \mathrm{C}$ NMR $\left(100 \mathrm{MHz}, \mathrm{CDCl}_{3}\right) \delta$ 221.7, 160.1, 138.1, 131.3, 127.7, 126.9, $113.8,101.6,74.6,67.4,58.2,55.5,41.7,38.0,35.8,35.1,33.7,33.6,29.9,29.9,26.9$, 25.5, 25.4; HRMS (MALDI-FTMS) calculated for [M+Na] ${ }^{+}$419.2193, found 419.2186.
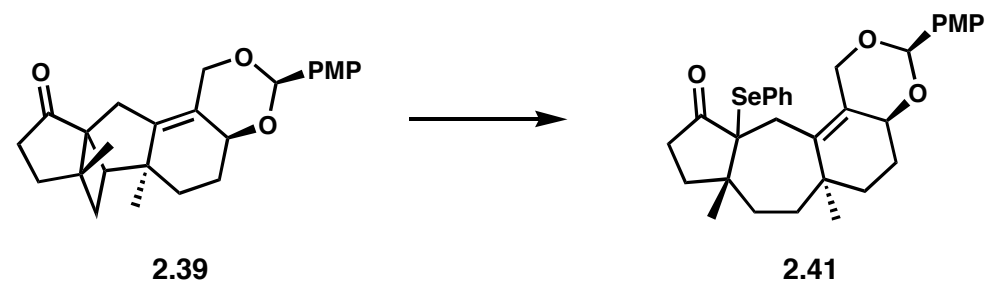

Selenide 2.41 (From Organic Letters 2002, 4, 2063-2066): To cyclobutane 2.39 (16.0 $\mathrm{mg}, 0.041 \mathrm{mmol})$ was added a $0.1 \mathrm{M}$ THF solution of $\mathrm{SmI}_{2}(0.85 \mathrm{~mL}, 0.085 \mathrm{mmol})$, quickly followed by HMPA $(0.05 \mathrm{~mL})$, and the mixture was stirred under argon for 5 min. The solution remained purple until $\mathrm{PhSeBr}(29 \mathrm{mg}, 0.122 \mathrm{mmol})$ in $0.3 \mathrm{~mL}$ dry THF was added. The reaction was quenched after 5 min with $\mathrm{pH}=7$ phosphate buffer (2 $\mathrm{mL})$, extracted with $\mathrm{CH}_{2} \mathrm{Cl}_{2}(3 \times 2 \mathrm{~mL})$, dried over $\mathrm{MgSO}_{4}$, and concentrated. Purification by flash chromatography $\left(\mathrm{SiO}_{2}, 0 \rightarrow 15 \%\right.$ EtOAc/hexanes $)$ on the crude 
product afforded $9.8 \mathrm{mg}(44 \%)$ of selenide 2.41 as a pale yellow oil. TLC: $R_{f}=0.29$ (20\% EtOAc/hexanes); IR (film) 2924, 2853, 1718, 1616, 1518, 1457, 1249, $1035 \mathrm{~cm}^{-1}$; ${ }^{1} \mathrm{H}$ NMR (500 MHz, $\mathrm{CDCl}_{3}$ ) $\delta 7.53(\mathrm{dd}, 2 \mathrm{H}), 7.47$ (d, $\left.J=8.6 \mathrm{~Hz}, 2 \mathrm{H}\right), 7.40(\mathrm{dd}, 1 \mathrm{H}), 7.31$ $(\mathrm{dd}, 2 \mathrm{H}), 6.91(\mathrm{~d}, J=8.6 \mathrm{~Hz}, 2 \mathrm{H}), 5.62(\mathrm{~s}, 1 \mathrm{H}), 5.48(\mathrm{~d}, J=12.7 \mathrm{~Hz}, 1 \mathrm{H}), 4.45(\mathrm{~d}, J=$ $12.7 \mathrm{~Hz}, 1 \mathrm{H}), 4.41(\mathrm{dd}, 1 \mathrm{H}), 3.80(\mathrm{~s}, 3 \mathrm{H}), 2.78(\mathrm{~m}, 1 \mathrm{H}), 2.71(\mathrm{~d}, J=16.7 \mathrm{~Hz}, 1 \mathrm{H}), 2.63$ (d, $J=16.7 \mathrm{~Hz}, 1 \mathrm{H}), 2.36(\mathrm{~m}, 1 \mathrm{H}), 2.16(\mathrm{~m}, 1 \mathrm{H}), 1.98(\mathrm{~m}, 3 \mathrm{H}), 1.69(\mathrm{~m}, 3 \mathrm{H}), 1.60(\mathrm{~m}$,

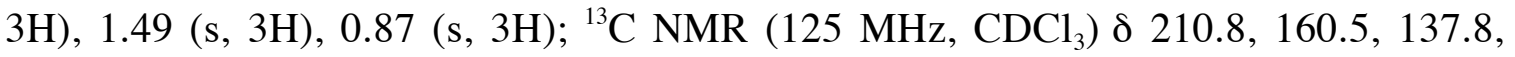
135.1, 131.6, 130.0, 129.5, 128.6, 128.2, 127.6, 114.2, 101.3, 69.2, 67.1, 55.7, 47.4, 38.4, 38.1, 36.9, 35.6, 35.6, 30.1, 28.0, 25.5, 23.1, 22.9, 14.5; HRMS (MALDI-FTMS) calculated for $[\mathrm{M}+\mathrm{Na}]^{+}$575.1671, found 575.1657.

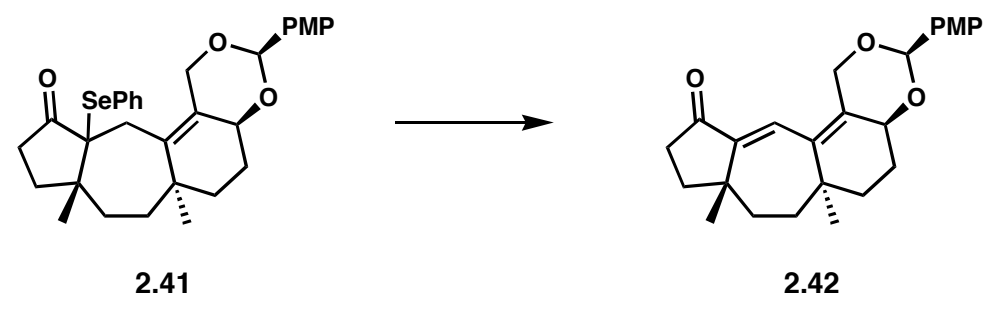

Dienone 2.42 (From Organic Letters 2002, 4, 2063-2066): Selenide 2.41 (25.0 mg, $0.045 \mathrm{mmol})$ in $1.8 \mathrm{~mL} \mathrm{CH}_{2} \mathrm{Cl}_{2}$ was cooled to $-78^{\circ} \mathrm{C}$ and $m \mathrm{CPBA}(8.6 \mathrm{mg}, 0.050 \mathrm{mmol})$ in $0.45 \mathrm{~mL} \mathrm{CH}_{2} \mathrm{Cl}_{2}$ was added dropwise. After $5 \mathrm{~min}$ the reaction was quenched at -78 ${ }^{\circ} \mathrm{C}$ by the dropwise addition of $1 \mathrm{~mL}$ of saturated aqueous $\mathrm{Na}_{2} \mathrm{~S}_{2} \mathrm{O}_{3}$. The mixture was allowed to warm to room temperature, and saturated aqueous $\mathrm{NaHCO}_{3}$ was added. The mixture was extracted with $\mathrm{Et}_{2} \mathrm{O}(3 \times 3 \mathrm{~mL})$, dried over $\mathrm{MgSO}_{4}$, and concentrated. Purification of the crude product by flash chromatography $\left(\mathrm{SiO}_{2}, 10 \rightarrow 20 \%\right.$ EtOAc/hexanes) afforded $15.0 \mathrm{mg}(84 \%)$ of dienone $\mathbf{2 . 4 2}$ as a colorless oil. TLC: $\mathrm{R}_{\mathrm{f}}=$ 0.28 (25\% EtOAc/hexanes); IR (film) 3418, 2936, 1716, 1615, 1517, 1364, 1249, 1122, 
1095, 1034, $829 \mathrm{~cm}^{-1} ;{ }^{1} \mathrm{H}$ NMR $\left(500 \mathrm{MHz}, \mathrm{CDCl}_{3}\right) \delta 7.40(\mathrm{~d}, J=8.8 \mathrm{~Hz}, 2 \mathrm{H}), 6.98(\mathrm{~s}$, $1 \mathrm{H}), 6.87(\mathrm{~d}, J=8.8 \mathrm{~Hz}, 2 \mathrm{H}), 5.60(\mathrm{~s}, 1 \mathrm{H}), 4.67(\mathrm{~d}, J=13.0 \mathrm{~Hz}, 1 \mathrm{H}), 4.45(\mathrm{dd}, 1 \mathrm{H}), 4.36$ $(\mathrm{d}, J=13.0 \mathrm{~Hz}, 1 \mathrm{H}), 3.79(\mathrm{~s}, 3 \mathrm{H}), 2.45(\mathrm{~m}, 2 \mathrm{H}), 2.04(\mathrm{~m}, 2 \mathrm{H}), 1.85(\mathrm{~m}, 3 \mathrm{H}), 1.66(\mathrm{~m}$, 4H), $1.41(\mathrm{~m}, 1 \mathrm{H}), 1.19(\mathrm{~s}, 3 \mathrm{H}), 0.98(\mathrm{~s}, 3 \mathrm{H}) ;{ }^{13} \mathrm{C} \mathrm{NMR}\left(125 \mathrm{MHz}, \mathrm{CDCl}_{3}\right) \delta 207.1$, $160.1,145.7,136.5,131.3,130.9,127.6,114.5,113.8,100.8,75.5,67.3,55.5,43.3,37.2$, 36.7, 36.6, 36.0, 35.3, 29.9, 26.7, 25.3, 24.0; HRMS (MALDI-FTMS) calculated for $[\mathrm{M}+\mathrm{Na}]^{+}$417.2036, found 417.2046.

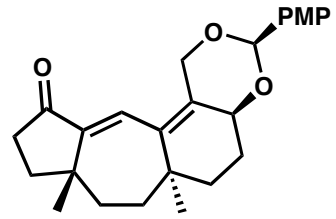

2.42

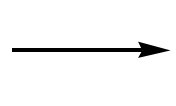

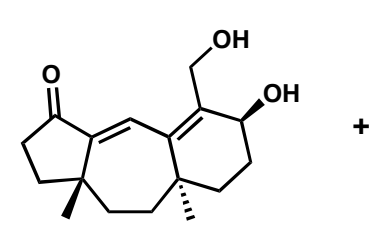

2.43

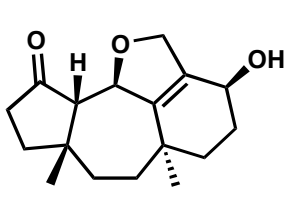

2.44

Diol 2.43, dihydrofuran 2.44 (From Organic Letters 2002, 4, 2063-2066): Dienone 2.42 (15.0 mg, $0.038 \mathrm{mmol}$ ) was dissolved in $0.38 \mathrm{~mL} \mathrm{CH}_{3} \mathrm{CN}$. PPTS $(2.4 \mathrm{mg}, 0.010$ mmol) was added, followed by $0.20 \mathrm{ml} \mathrm{H}_{2} \mathrm{O}$, and the mixture was stirred for $7 \mathrm{~h}$ under argon. The reaction was then quenched with saturated aqueous $\mathrm{NaHCO}_{3}(1 \mathrm{~mL})$ and extracted with $\mathrm{CH}_{2} \mathrm{Cl}_{2}(3 \times 1 \mathrm{~mL})$. Combined organic extracts were dried over $\mathrm{MgSO}_{4}$ and concentrated. Crude ${ }^{1} \mathrm{H}$ NMR and TLC analysis showed predominantly diol $\mathbf{2 . 4 3}$ as the product of the reaction. Diol $\mathbf{2 . 4 3}$ slowly isomerizes to dihydrofuran $\mathbf{2 . 4 4}$, and the conversion is accelerated by silica gel. Thus, purification by flash chromatography $\left(\mathrm{SiO}_{2}\right.$, $60 \rightarrow 80 \%$ EtOAc/hexanes) afforded $5.1 \mathrm{mg}(49 \%)$ of diol $\mathbf{2 . 4 3}$ as a colorless oil and 4.7 mg (45\%) of dihydrofuran $\mathbf{2 . 4 4}$ as a colorless oil. $\mathbf{2 . 4 3}$ : TLC: $\mathrm{R}_{\mathrm{f}}=0.26(80 \%$ EtOAc/hexanes); IR (film) 3392, 2925, 2854, 1700, 1625, 1456, $1051 \mathrm{~cm}^{-1} ;{ }^{1} \mathrm{H}$ NMR 
(500 MHz, $\left.\mathrm{CDCl}_{3}\right) \delta 7.03(\mathrm{~s}, 1 \mathrm{H}), 4.44(\mathrm{br}, 1 \mathrm{H}), 4.32(\mathrm{br}, 2 \mathrm{H}), 2.42(\mathrm{~m}, 3 \mathrm{H}), 2.35(\mathrm{~m}$, 1H), $1.79(\mathrm{~m}, 4 \mathrm{H}), 1.73-1.59(\mathrm{~m}, 4 \mathrm{H}), 1.10(\mathrm{~s}, 3 \mathrm{H}), 0.97$ (s, 3H); HRMS (MALDIFTMS) calculated for $[\mathrm{M}+\mathrm{Na}]^{+} 299.1618$, found 299.1622. 2.44: $\mathrm{TLC}: \mathrm{R}_{\mathrm{f}}=0.38(80 \%$ EtOAc/hexanes); IR (film) 3401, 2927, 2853, 1738, $1062 \mathrm{~cm}^{-1}$; ${ }^{1} \mathrm{H}$ NMR (500 MHz, $\left.\mathrm{CDCl}_{3}\right) \delta 5.15(\mathrm{~m}, 1 \mathrm{H}), 4.81(\mathrm{dd}, J=12.1,5.5 \mathrm{~Hz}, 1 \mathrm{H}), 4.48(\mathrm{ddd}, J=12.1,3.3,1.1 \mathrm{~Hz}$, 1H), $4.26(\mathrm{br}, 1 \mathrm{H}), 2.35(\mathrm{~m}, 2 \mathrm{H}), 2.18(\mathrm{~d}, J=5.1 \mathrm{~Hz}, 1 \mathrm{H}), 1.99(\mathrm{~m}, 1 \mathrm{H}), 1.79(\mathrm{~m}, 3 \mathrm{H})$, $1.72(\mathrm{~m}, 2 \mathrm{H}), 1.60(\mathrm{~m}, 1 \mathrm{H}), 1.46(\mathrm{~m}, 2 \mathrm{H}), 1.31(\mathrm{~m}, 1 \mathrm{H}), 1.16(\mathrm{~s}, 3 \mathrm{H}), 0.94(\mathrm{~s}, 3 \mathrm{H}) ;{ }^{13} \mathrm{C}$ NMR (125 MHz, $\left.\mathrm{CDCl}_{3}\right) \delta$ 216.6, 142.8, 125.7, 81.8, 74.1, 65.3, 64.3, 41.7, 37.5, 36.3, 34.9, 34.3, 33.7, 29.8, 29.5, 26.7, 24.3; HRMS (MALDI-FTMS) calculated for [M+Na $]^{+}$ 299.1618, found 299.1619.

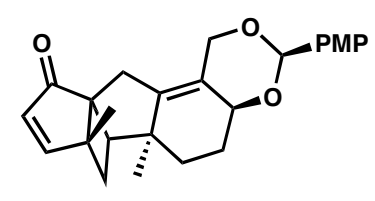

2.45

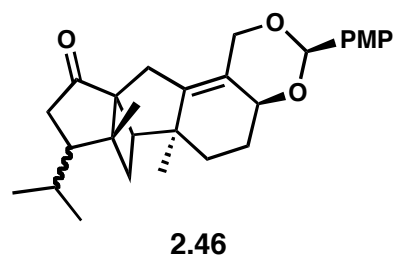

2.46

Cyclobutane 2.46: $\mathrm{LiCl}(0.7 \mathrm{mg}, 0.016 \mathrm{mmol})$ and $\mathrm{CuI}(1.6 \mathrm{mg}, 0.008 \mathrm{mmol})$ were flame-dried in a vial, and the mixture of solids was dissolved in $0.4 \mathrm{~mL}$ dry THF. After cooling to $-78^{\circ} \mathrm{C}$, chlorotrimethylsilane $(29 \mathrm{mg}, 34 \mu \mathrm{L}, 0.27 \mathrm{mmol}$ ) was added, followed by enone 2.45 ( $21 \mathrm{mg}, 0.054 \mathrm{mmol}$ ) in $0.8 \mathrm{~mL}$ dry THF. After stirring for $10 \mathrm{~min}$, a 2.0 M THF solution of $i-\mathrm{PrMgCl}(135 \mu \mathrm{L}, 0.27 \mathrm{mmol})$ was added until TLC showed complete consumption of $\mathbf{2 . 4 5}$. The reaction was quenched with saturated aq. $\mathrm{NH}_{4} \mathrm{Cl}$ and allowed to warm to rt. The mixture was extracted with $\mathrm{Et}_{2} \mathrm{O}(3 \mathrm{x})$. Extracts were treated with $0.7 \mathrm{~mL}$ of a $1.0 \mathrm{M}$ THF solution of TBAF. Saturated aq. $\mathrm{NaHCO}_{3}$ was added and the mixture was extracted with $\mathrm{CH}_{2} \mathrm{Cl}_{2}(3 \mathrm{x})$. Extracts were dried over $\mathrm{MgSO}_{4}$ and 
concentrated. Purification of the crude product by flash chromatography $\left(\mathrm{SiO}_{2}, 10 \rightarrow\right.$ 12\% EtOAc/hexanes) afforded $20.3 \mathrm{mg}(87 \%)$ of a $c a .1: 1$ mixture of cyclobutanes $\mathbf{2 . 4 6}$ as a colorless oil.

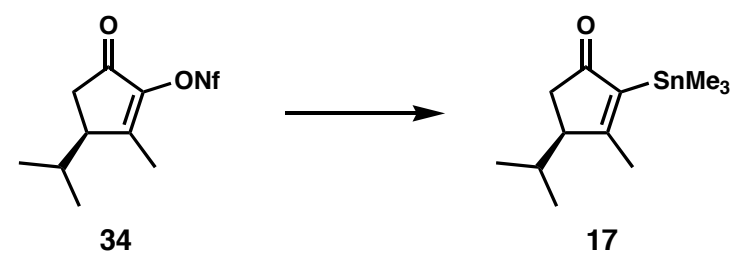

Vinylstannane 17 (Step b from Scheme 9): To nonaflate 34 (474 mg, $1.09 \mathrm{mmol})$ in a vial was added [1,1-bis(diphenylphosphino)ferrocene]dichloropalladium (178 mg, 0.22 mmol). The mixture was dissolved in $11 \mathrm{~mL}$ dry NMP. Hexamethylditin $(0.806 \mathrm{~mL}$, $2.72 \mathrm{mmol}$ ) was added and the golden mixture was heated at $60{ }^{\circ} \mathrm{C}$. After $8 \mathrm{~h}$, the reaction was cooled to room temperature and diluted with hexanes. The mixture was washed with $\mathrm{H}_{2} \mathrm{O}$, sat. aq. $\mathrm{NaHCO}_{3}$, and brine. The organic layer was dried over $\mathrm{MgSO}_{4}$ and concentrated. Purification of the crude product by flash chromatography $\left(\mathrm{SiO}_{2}, 5 \rightarrow\right.$ 15\% EtOAc/hexanes) afforded $205 \mathrm{mg}(63 \%)$ of vinylstannane $\mathbf{1 7}$ as a colorless oil, 52 $\mathrm{mg}(11 \%)$ of recovered nonaflate $\mathbf{3 4}$, and $27 \mathrm{mg}(16 \%)$ of diosphenol $\mathbf{2 5}$ (desulfonylation product). TLC: $\mathrm{R}_{\mathrm{f}}=0.55$ (15\% EtOAc/hexanes); IR (film) 2959, 1682, 1589, 1253, 773, $528 \mathrm{~cm}^{-1} ;{ }^{1} \mathrm{H}$ NMR $\left(400 \mathrm{MHz}, \mathrm{CDCl}_{3}\right) \delta 2.84(\mathrm{~m}, 1 \mathrm{H}), 2.24(\mathrm{dd}, J=6.8,18.4 \mathrm{~Hz}, 1 \mathrm{H})$, $2.13(\mathrm{~m}, 2 \mathrm{H}), 2.06(\mathrm{~s}, 3 \mathrm{H}), 0.97(\mathrm{~d}, 6.8 \mathrm{~Hz}, 3 \mathrm{H}), 0.59(\mathrm{~d}, 7.2 \mathrm{~Hz}, 3 \mathrm{H}), 0.24(\mathrm{~s}, 9 \mathrm{H}) ;{ }^{13} \mathrm{C}$ NMR (100 MHz, $\left.\mathrm{CDCl}_{3}\right) \delta$ 214.0, 188.2, 143.5, 53.0, 35.9, 27.6, 21.8, 18.9, 14.6, -8.9; $[\alpha]^{20}{ }_{\mathrm{D}}=+19.2\left(\mathrm{c}=2.35, \mathrm{CHCl}_{3}\right)$; HRMS (EI) calculated for $\left[\mathrm{M}-\mathrm{CH}_{3}\right]^{+} 287.0458$, found 287.0459 . 


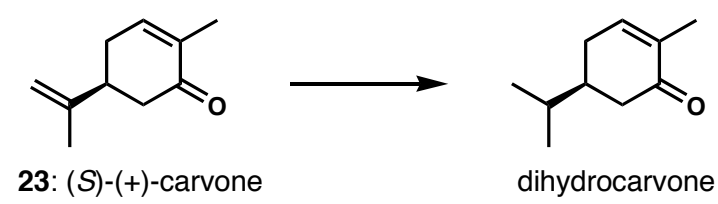

Dihydrocarvone (Step a from Scheme 7): A dry $100 \mathrm{~mL}$ round-bottom flask was charged with $\mathrm{PtO}_{2}(45 \mathrm{mg}, 0.2 \mathrm{mmol})$. (S)-(+)-Carvone 3.6 (15.7 mL, $\left.15.0 \mathrm{~g}, 100 \mathrm{mmol}\right)$ was added to the flask, which was evacuated and filled with $\mathrm{H}_{2}$ gas three times. The brown mixture was vigorously stirred under $\mathrm{H}_{2}$ balloon pressure. After $23 \mathrm{~h},{ }^{1} \mathrm{H}$ NMR analysis of a small sample of the reaction showed complete reduction. The mixture was filtered through a short pad of silica gel with diethyl ether. The filtrate was concentrated to give $15.3 \mathrm{~g}$ (100\% yield) of dihydrocarvone as a pale brown oil. The crude product could be distilled at reduced pressure ( $\mathrm{bp}=94^{\circ} \mathrm{C}$ at 26 Torr) to give a colorless oil, but it was usually taken on to the next step in crude form.

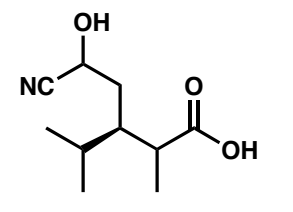

28

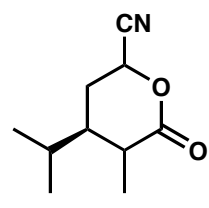

24

$\boldsymbol{\alpha}$-Acyloxynitriles 24 (from Scheme 7): Cyanohydrin carboxylic acids 28 (8.57 g, 43 mmol) were dissolved in $86 \mathrm{~mL}$ dry $\mathrm{CH}_{2} \mathrm{Cl}_{2}$, cooled to $0{ }^{\circ} \mathrm{C}$, and EDCI $(9.89 \mathrm{~g}, 52 \mathrm{mmol})$ was added. The reaction was allowed to warm to room temperature. After $7 \mathrm{~h}$ when TLC (eluted in 50\% EtOAc/hexanes, stained with $\mathrm{KMnO}_{4}$ ) indicated completion, the reaction was quenched with $100 \mathrm{~mL} 1 \mathrm{~N}$ aq. $\mathrm{HCl}$ and extracted with $\mathrm{CH}_{2} \mathrm{Cl}_{2}$ (3x). Extracts were dried over $\mathrm{MgSO}_{4}$ and concentrated. The crude material was filtered through a $\mathrm{SiO}_{2}$ plug with 50\% EtOAc/hexanes to give $6.13 \mathrm{~g}$ (79\%) of lactones 24 in a $\left(1^{\mathrm{A}}: 1.4^{\mathrm{B}}: 1.9^{\mathrm{C}}: 1.3^{\mathrm{D}}\right)$ ratio as a pale yellow viscous oil. Selected data for the mixture: 
TLC: $\mathrm{R}_{\mathrm{f}}=$ 0.52-0.64 (50\% EtOAc/hexanes); IR (film) 2964, 1756, 1467, 1375, 1229, 1174, 1093, $1033 \mathrm{~cm}^{-1} ;{ }^{1} \mathrm{H}$ NMR (400 $\left.\mathrm{MHz}, \mathrm{CDCl}_{3}\right)$ diagnostic peak(s) $\delta 5.29(\mathrm{dd}, J=$ 2.0, $6.0 \mathrm{~Hz}, 1 \mathrm{H}, \mathrm{A}), 5.20$ (app t, $J=4.8 \mathrm{~Hz}, 1 \mathrm{H}, \mathrm{B}), 5.10(\mathrm{dd}, J=4.6,9.4 \mathrm{~Hz}, 1 \mathrm{H}, \mathrm{C})$, $5.02(\mathrm{dd}, J=4.0,12.4 \mathrm{~Hz}, 1 \mathrm{H}, \mathrm{D})$; HRMS (EI) calculated for $[\mathrm{M}]^{+} 181.1103$, found 181.1112 .

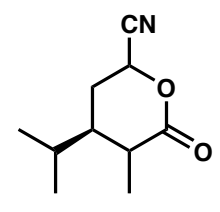

24

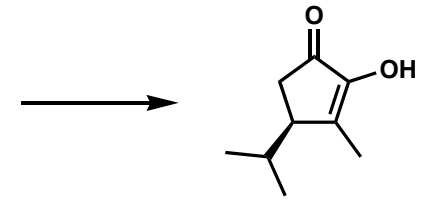

25

Diosphenol 25 (Step f from Scheme 7): $\alpha$-Acyloxynitriles 24 (5.10 g, $28.1 \mathrm{mmol}$ ) was dissolved in $550 \mathrm{ml}$ dry THF and a $1 \mathrm{M}$ solution of lithium bis(trimethylsilyl)amide in THF (84.4 mL) was slowly added at room temperature. The pale yellow solution darkened to a deep red. After $2 \mathrm{~h}$, the reaction was quenched with $\sim 500 \mathrm{~mL}$ of $1 \mathrm{~N}$ aq. $\mathrm{HCl}$ (lowering $\mathrm{pH}$ to $\sim$ ). The layers were separated and the aqueous was extracted with $\mathrm{CH}_{2} \mathrm{Cl}_{2}(3 \mathrm{x})$. Combined organic layers were dried over $\mathrm{MgSO}_{4}$ and concentrated, giving a viscous brown-black oil as the crude product. Purification by flash chromatography $\left(\mathrm{SiO}_{2}, 10 \rightarrow 15 \% \mathrm{EtOAc/hexanes)}\right.$ afforded $2.25 \mathrm{~g}(52 \%)$ of diosphenol 25 as a yellow solid. This material could be crystallized to a highly pure white crystalline state. $\mathrm{mp}=88$ ${ }^{\circ} \mathrm{C}$; TLC: $\mathrm{R}_{\mathrm{f}}=0.33$ (30\% EtOAc/hexanes); IR (film) 3293, 2961, 1698, 1653, 1404, 1360, 1204, $1120 \mathrm{~cm}^{-1} ;{ }^{1} \mathrm{H}$ NMR (400 MHz, $\left.\mathrm{CDCl}_{3}\right) \delta 6.23(\mathrm{~s}, 1 \mathrm{H}), 2.67(\mathrm{~m}, 1 \mathrm{H}), 2.29$ (dd, $J=19.8,6.4 \mathrm{~Hz}, 1 \mathrm{H}), 2.13(\mathrm{~m}, 1 \mathrm{H}), 2.12(\mathrm{dm}, J=19.8 \mathrm{~Hz}, 1 \mathrm{H}), 1.94(\mathrm{~s}, 3 \mathrm{H}), 0.97$ $(\mathrm{d}, 3 \mathrm{H}), 0.62(\mathrm{~d}, 3 \mathrm{H}) ;{ }^{13} \mathrm{C} \mathrm{NMR}\left(100 \mathrm{MHz}, \mathrm{CDCl}_{3}\right) \delta 202.6,149.5,147.0,44.1,32.9$, 
27.6, 21.1, 14.8, 12.4; $[\alpha]^{20}{ }_{\mathrm{D}}=+6.1\left(\mathrm{c}=0.59, \mathrm{CHCl}_{3}\right) ; \mathrm{HRMS}(\mathrm{EI})$ calculated for $[\mathrm{M}]^{+}$ 154.0994, found 154.1005 .

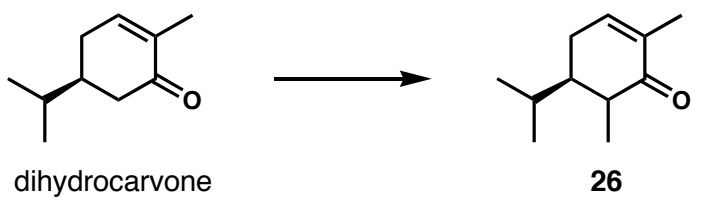

Enones 26 (Step b from Scheme 7): LDA was prepared: Diisopropylamine (15.4 mL, $110 \mathrm{mmol}$ ) was placed in a $1 \mathrm{~L}$ flask and dissolved in $400 \mathrm{~mL}$ dry THF, then cooled to 0 ${ }^{\circ} \mathrm{C} .2 .5 \mathrm{M} \mathrm{n}$-BuLi in hexanes (44 mL, $110 \mathrm{mmol}$ ) was added slowly and the solution was stirred for $30 \mathrm{~min}$, then cooled to $-78^{\circ} \mathrm{C}$. Dihydrocarvone $(15.3 \mathrm{~g}, 100 \mathrm{mmol})$ in $100 \mathrm{~mL}$ dry $\mathrm{THF}$, precooled to $-78{ }^{\circ} \mathrm{C}$, was slowly added via cannula. The solution was stirred for $1 \mathrm{~h}$ at $-78{ }^{\circ} \mathrm{C}$, then $1 \mathrm{~h}$ at $0{ }^{\circ} \mathrm{C}$. Iodomethane $(12.5 \mathrm{~mL}, 28.4 \mathrm{~g}, 200 \mathrm{mmol})$ was added and the solution was stirred for $90 \mathrm{~min}$ at $0{ }^{\circ} \mathrm{C}$, then at $\mathrm{rt}$ for $15 \mathrm{~h}$. THF was removed from the brown mixture in vacuo, then sat. aq. $\mathrm{NH}_{4} \mathrm{Cl}$ was added and the mixture was extracted with diethyl ether (3x). Extracts were dried over $\mathrm{MgSO}_{4}$ and concentrated. The material was transferred to a $100 \mathrm{~mL}$ round-bottom flask and distilled $\left(\mathrm{bp}=95^{\circ} \mathrm{C}\right.$ at 10 Torr), giving $15.97 \mathrm{~g}$ (96\% yield for 2 steps) of a $5.5: 1$ mixture of diastereoisomers 26 as a fragrant colorless oil. Selected data for the mixture: TLC: $\mathrm{R}_{\mathrm{f}}=0.45,0.50(10 \%$ EtOAc/hexanes); IR (film) 2962, 1710, 1673, 1456, $1368 \mathrm{~cm}^{-1} ;{ }^{1} \mathrm{H}$ NMR (400 MHz, $\left.\mathrm{CDCl}_{3}\right) \operatorname{diagnostic}$ peak $(\mathrm{s}) \delta 6.73(\mathrm{~m}, 1 \mathrm{H}$, minor component), $6.66(\mathrm{~m}, 1 \mathrm{H}$, major component); HRMS (EI) calculated for [M] ${ }^{+}$166.1358, found 166.1358. 


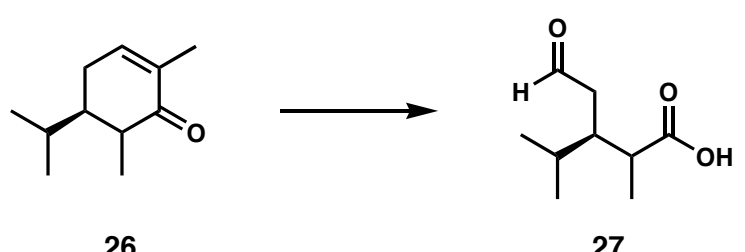

26

27

Aldehyde carboxylic acids 27 (Step c from Scheme 7): Enones 26 (15.03 g, 90.4 mmol) were dissolved in $200 \mathrm{~mL}$ ethyl acetate and treated with ozone at $-78^{\circ} \mathrm{C}$. When a deep blue color was observed after 90 minutes, oxygen was bubbled through the mixture until the blue color dissipated. The reaction was warmed to $0{ }^{\circ} \mathrm{C}$ and nitrogen was bubbled through the mixture for 15 minutes. Palladium (10\%) on activated carbon $(0.4 \mathrm{~g})$ was added and the reaction was stirred vigorously under hydrogen for $17 \mathrm{~h}$. The mixture was filtered through a pad of Celite with ethyl acetate, and the filtrate was concentrated. Purification of the crude product by flash chromatography $\left(\mathrm{SiO}_{2}, 30 \rightarrow 40 \%\right.$ EtOAc/hexanes) afforded $7.46 \mathrm{~g}(48 \%)$ of aldehyde carboxylic acids 27 as a colorless oil. Selected data for the mixture: TLC: $\mathrm{R}_{\mathrm{f}}=0.29$ (50\% EtOAc/hexanes); IR (film) 3650-2500, 2963, 1713, 1466, 1390, 1180, $1034 \mathrm{~cm}^{-1} ;{ }^{1} \mathrm{H}$ NMR (400 MHz, $\mathrm{CDCl}_{3}$ ) diagnostic peak(s) $\delta 9.71$ (app s, $1 \mathrm{H}$ ); HRMS (EI) calculated for $\left[\mathrm{M}-\mathrm{H}^{+}\right]$171.1021, found 171.1015 .

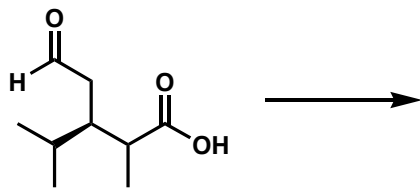

27

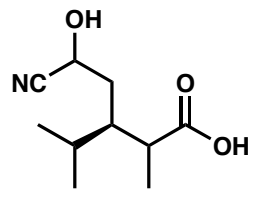

28

Cyanohydrins 28 (Step d from Scheme 7): Aldehyde carboxylic acids 27 (7.46 g, 43.3 mmol) were dissolved in $150 \mathrm{~mL}$ 4:1 $\mathrm{THF}-\mathrm{H}_{2} \mathrm{O}$. Sodium cyanide $(3.18 \mathrm{~g}, 65.0 \mathrm{mmol})$ and $p$-toluene sulfonic acid monohydrate $(12.4 \mathrm{~g}, 65 \mathrm{mmol})$ were added. After stirring 
for $14 \mathrm{~h}$, THF was removed in vacuo. The aqueous residue was extracted with $\mathrm{CH}_{2} \mathrm{Cl}_{2}$ (3x) and extracts were washed with brine, dried over $\mathrm{MgSO}_{4}$, and concentrated to give $8.57 \mathrm{~g}(99 \%)$ of a pale yellow viscous oil that was taken on to the next step in crude form. On large scale, ${ }^{1} \mathrm{H}$ NMR showed a significant amount of the $\alpha$-acyloxycyanohydrin resulting from cyclization of the cyanohydrin onto the carboxylic acid. Selected data for the mixture: TLC: $R_{f}=0.05-0.28$ (streak) (50\% EtOAc/hexanes); IR (film) 3650-2500, 2964, 1746, 1468, 1374, 1229, 1174, $1093 \mathrm{~cm}^{-1} ;{ }^{1} \mathrm{H} \mathrm{NMR}\left(400 \mathrm{MHz}, \mathrm{CDCl}_{3}\right)$ diagnostic $\operatorname{peak}(\mathrm{s}) \delta 4.51(\mathrm{~m}, 1 \mathrm{H})$.

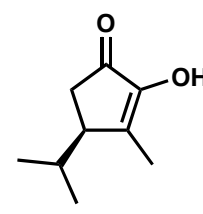

25

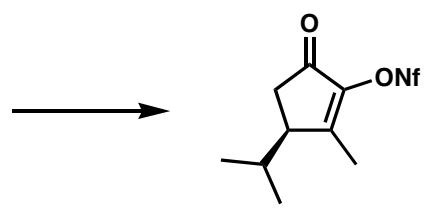

34

Nonaflate 34 (Step a from Scheme 9): Diosphenol 25 (145 mg, $0.94 \mathrm{mmol}$ ) was dissolved in $5.0 \mathrm{~mL}$ dry $\mathrm{CH}_{2} \mathrm{Cl}_{2}$. Triethylamine $(0.144 \mathrm{~mL}, 1.03 \mathrm{mmol})$ was added, followed by perfluorobutanesulfonyl fluoride $(0.253 \mathrm{~mL}, 1.41 \mathrm{mmol})$. After $14 \mathrm{~h}$, the reaction was washed with $\mathrm{H}_{2} \mathrm{O}$ and brine. The organic layer was dried over $\mathrm{MgSO}_{4}$ and concentrated. Purification of the black crude product by flash chromatography $\left(\mathrm{SiO}_{2}, 10\right.$ $\rightarrow 15 \%$ EtOAc/hexanes) afforded $384 \mathrm{mg}(94 \%)$ of nonaflate 34 as a pale yellow oil that hardened to a yellow solid when stored in the refrigerator. This material could be crystallized to a highly pure white crystalline state. $\mathrm{mp}=49{ }^{\circ} \mathrm{C}$; TLC: $\mathrm{R}_{\mathrm{f}}=0.36(15 \%$ EtOAc/hexanes); IR (film) 2965, 1732, 1660, 1427, 1280, 1144, 1068, $1035 \mathrm{~cm}^{-1} ;{ }^{1} \mathrm{H}$ NMR (400 MHz, $\left.\mathrm{CDCl}_{3}\right) \delta 2.87(\mathrm{~m}, 1 \mathrm{H}), 2.40(\mathrm{dd}, J=19.2,6.4 \mathrm{~Hz}, 1 \mathrm{H}), 2.26$ (dd, $J=$ $19.2 \mathrm{~Hz}, 1.6 \mathrm{~Hz}, 1 \mathrm{H}), 2.23(\mathrm{~m}, 1 \mathrm{H}), 2.10(\mathrm{~s}, 3 \mathrm{H}), 1.03(\mathrm{~d}, 3 \mathrm{H}), 0.69(\mathrm{~d}, 3 \mathrm{H}) ;{ }^{13} \mathrm{C} \mathrm{NMR}$ 
$\left(100 \mathrm{MHz}, \mathrm{CDCl}_{3}\right) \delta 196.1,166.5,145.0,44.7,32.9,27.8,20.9,14.6,13.8 ;[\alpha]^{20}{ }_{\mathrm{D}}=-8.4$ $\left(\mathrm{c}=0.95, \mathrm{CHCl}_{3}\right)$; HRMS (EI) calculated for $[\mathrm{M}]^{+}$436.0391, found 436.0387.

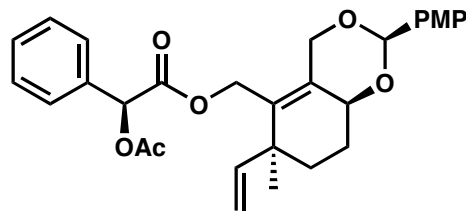

39

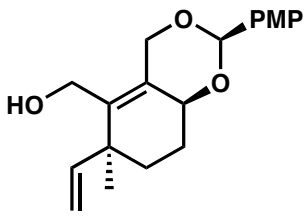

38

Allylic alcohol 38 (Step a from Scheme 11): Mandelate ester 39 (321 mg, $0.65 \mathrm{mmol}$ ) was dissolved in $13 \mathrm{~mL} \mathrm{MeOH}$ and potassium carbonate (18 $\mathrm{mg}, 0.13 \mathrm{mmol})$ was added. After stirring for 30 minutes, TLC showed complete solvolysis of the esters. The reaction was quenched with saturated aq. ammonium chloride and extracted with $\mathrm{CH}_{2} \mathrm{Cl}_{2}$ (3x). Extracts were dried over $\mathrm{MgSO}_{4}$, filtered, and concentrated. Purification by flash chromatography $\left(\mathrm{SiO}_{2}, 20 \rightarrow 30 \%\right.$ EtOAc/hexanes) on the crude product afforded 201 mg $(97 \%)$ of enantiopure allylic alcohol 38 as a white solid. $[\alpha]^{20}{ }_{D}=+91.2(\mathrm{c}=0.43$, $\left.\mathrm{CHCl}_{3}\right)$

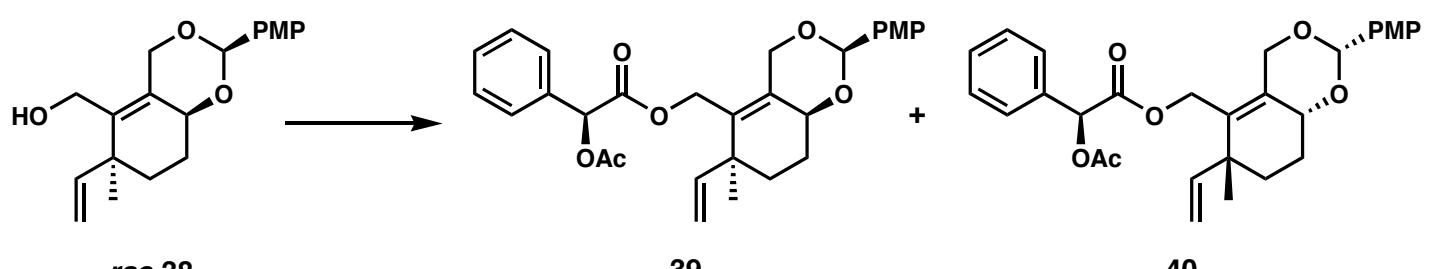

rac-38

39

40

Mandelic esters 39 and 40 (Step a from Scheme 10): Racemic allylic alcohol 38 (695 $\mathrm{mg}, 2.2 \mathrm{mmol}), O$-acetylmandelic acid $37(427 \mathrm{mg}, 2.2 \mathrm{mmol})$, and $N, N$ dimethylaminopyridine (24 mg, $0.2 \mathrm{mmol}$ ) were dissolved in $10 \mathrm{~mL}$ dry $\mathrm{CH}_{2} \mathrm{Cl}_{2}$ and the mixture was cooled to $0{ }^{\circ} \mathrm{C}$. Dicyclohexylcarbodiimide (454 mg, $\left.2.2 \mathrm{mmol}\right)$ in $1.5 \mathrm{~mL}$ dry $\mathrm{CH}_{2} \mathrm{Cl}_{2}$ was added dropwise (a white precipitate formed during the addition) and the 
reaction was stirred for 90 minutes. The precipitate (dicyclohexylurea) was filtered off with $\mathrm{CH}_{2} \mathrm{Cl}_{2}$ and the filtrate was washed with $30 \mathrm{~mL}$ saturated aq. $\mathrm{NaHCO}_{3}, 30 \mathrm{~mL}$ brine, dried over $\mathrm{MgSO}_{4}$, filtered, and concentrated. The crude product was purified by flash chromatography $\left(\mathrm{SiO}_{2}, 49: 49: 2\right.$ toluene/ $\left.\mathrm{CH}_{2} \mathrm{Cl}_{2} / \mathrm{Et}_{2} \mathrm{O}\right)$ to afford $324 \mathrm{mg}$ of 39, $321 \mathrm{mg}$ of the 40, and $412 \mathrm{mg}$ of mixed material, overall $1.057 \mathrm{~g}(98 \%)$, as colorless viscous oils. The diastereoisomers could also be separated by preparative thin layer chromatography $\left(\mathrm{SiO}_{2}, 48: 48: 4\right.$ toluene/ $\left.\mathrm{CH}_{2} \mathrm{Cl}_{2} / \mathrm{Et}_{2} \mathrm{O}\right)$. Compound 39: $\mathrm{TLC}: \quad \mathrm{R}_{\mathrm{f}}=0.41(48: 48: 4$ toluene/ $\mathrm{CH}_{2} \mathrm{Cl}_{2} / \mathrm{Et}_{2} \mathrm{O}$ ); IR (film) 2932, 1743, 1614, 1516, 1370, 1248, 1172, 1094, 1034 $\mathrm{cm}^{-1} ;{ }^{1} \mathrm{H} \mathrm{NMR}\left(400 \mathrm{MHz}, \mathrm{CDCl}_{3}\right) \delta 7.40(\mathrm{~m}, 7 \mathrm{H}), 6.88(\mathrm{~d}, J=8.5 \mathrm{~Hz}, 2 \mathrm{H}), 5.87(\mathrm{~s}, 1$ H), $5.67(\mathrm{dd}, J=17.6,10.3 \mathrm{~Hz}, 1 \mathrm{H}), 5.58(\mathrm{~s}, 1 \mathrm{H}), 5.04(\mathrm{~d}, J=10.3 \mathrm{~Hz}, 1 \mathrm{H}), 4.86(\mathrm{~d}, J$ $=17.3 \mathrm{~Hz}, 1 \mathrm{H}), 4.68(\mathrm{~d}, J=12.3 \mathrm{~Hz}, 1 \mathrm{H}), 4.59(\mathrm{~d}, J=14.1 \mathrm{~Hz}, 1 \mathrm{H}), 4.44(\mathrm{~s}, J=12.3$ $\mathrm{Hz}, 1 \mathrm{H}), 4.38(\mathrm{dd}, J=9.7,6.4 \mathrm{~Hz}, 1 \mathrm{H}), 3.97(\mathrm{~d}, J=14.1 \mathrm{~Hz}, 1 \mathrm{H}), 3.79(\mathrm{~s}, 3 \mathrm{H}), 2.21(\mathrm{~s}$, $3 \mathrm{H}), 1.92(\mathrm{~m}, 1 \mathrm{H}), 1.76(\mathrm{~m}, 1 \mathrm{H}), 1.61(\mathrm{~m}, 1 \mathrm{H}), 1.47(\mathrm{~m}, 1 \mathrm{H}) ;{ }^{13} \mathrm{C}$ NMR $(100 \mathrm{MHz}$, $\left.\mathrm{CDCl}_{3}\right) \delta 170.2,168.3,160.0,143.6,135.9,133.6,131.0,130.6,129.3,128.8,127.5$, $127.4,114.6,113.6,100.5,75.1,74.5,66.1,60.8,55.3,42.0,34.1,25.6,24.6,20.7 ;[\alpha]^{20}$ $=+93.8\left(\mathrm{c}=2.00, \mathrm{CHCl}_{3}\right) ; \mathrm{HRMS}(\mathrm{EI})$ calculated for $[\mathrm{M}]$ 492.2148, found 492.2154. Compound 40: TLC: $\mathrm{R}_{\mathrm{f}}=0.33$ (48:48:4 toluene/ $\mathrm{CH}_{2} \mathrm{Cl}_{2} / \mathrm{Et}_{2} \mathrm{O}$ ); IR (film) 2936, 1743, 1614, 1517, 1370, 1248, 1172, 1094, $1035 \mathrm{~cm}^{-1} ;{ }^{1} \mathrm{H}$ NMR $\left(400 \mathrm{MHz}, \mathrm{CDCl}_{3}\right) \delta 7.41$ (m, 7 H), $6.89(\mathrm{~d}, J=8.8 \mathrm{~Hz}, 2 \mathrm{H}), 5.85(\mathrm{~s}, 1 \mathrm{H}), 5.65(\mathrm{dd}, J=17.3 \mathrm{~Hz}, 10.6 \mathrm{~Hz}, 1 \mathrm{H}), 5.64(\mathrm{~s}$, $1 \mathrm{H}), 5.05(\mathrm{~d}, J=10.6 \mathrm{~Hz}, 1 \mathrm{H}), 4.86(\mathrm{~d}, J=17.3 \mathrm{~Hz}, 1 \mathrm{H}), 4.82(\mathrm{~m}, 2 \mathrm{H}), 4.43(\mathrm{~m}, 1 \mathrm{H})$, $4.30(\mathrm{~m}, 2 \mathrm{H}), 3.79(\mathrm{~s}, 3 \mathrm{H}), 2.20(\mathrm{~s}, 3 \mathrm{H}), 1.92(\mathrm{~m}, 1 \mathrm{H}), 1.77(\mathrm{~m}, 1 \mathrm{H}), 1.58(\mathrm{~m}, 1 \mathrm{H})$, $1.44(\mathrm{~m}, 1 \mathrm{H}), 0.86(\mathrm{~s}, 3 \mathrm{H}) ;{ }^{13} \mathrm{C}$ NMR $\left(100 \mathrm{MHz} \mathrm{CDCl}_{3}\right) \delta 170.3,168.3,159.9,143.6$, $136.1,133.5,130.9,130.6,129.2,128.7,127.5,127.4,114.6,113.6,100.6,75.1,74.5$, 
$66.4,60.8,55.3,41.9,34.1,25.3,24.7,20.7 ;[\alpha]^{20}{ }_{D}=-48.9\left(\mathrm{c}=1.84, \mathrm{CHCl}_{3}\right) ; \mathrm{HRMS}$ (EI) calculated for $[\mathrm{M}]^{+}$492.2148, found 492.2124.

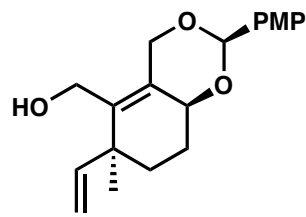

38

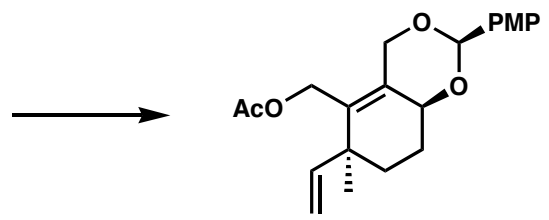

41

Allylic acetate 41 (Step b from Scheme 11): Enantiopure allylic alcohol 38 (201 mg, $0.64 \mathrm{mmol})$ was dissolved in $6 \mathrm{~mL}$ dry pyridine. Acetic anhydride $(0.12 \mathrm{~mL}, 1.27 \mathrm{mmol})$ and a catalytic amount of DMAP $(\sim 4 \mathrm{mg})$ were added. The reaction was stirred under argon for $15 \mathrm{~min}$. Saturated aqueous $\mathrm{NH}_{4} \mathrm{Cl}(6 \mathrm{~mL})$ was added, and the mixture was extracted with $\mathrm{CH}_{2} \mathrm{Cl}_{2}(3 \times 10 \mathrm{~mL})$. Combined organic extracts were washed with brine, dried over $\mathrm{MgSO}_{4}$, and concentrated. The crude product was filtered through a short pad of silica gel with $\mathrm{Et}_{2} \mathrm{O}$, giving $224 \mathrm{mg}$ (98\%) of allylic acetate $\mathbf{4 1}$ as a nearly colorless oil. $[\alpha]^{20}{ }_{\mathrm{D}}=+122.2\left(\mathrm{c}=0.37, \mathrm{CHCl}_{3}\right)$.

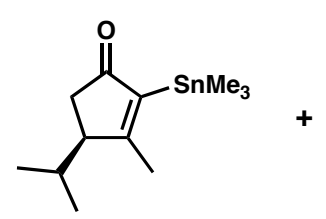

17

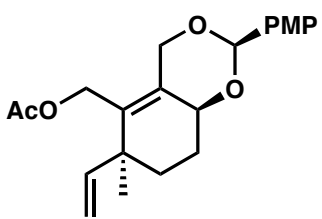

41

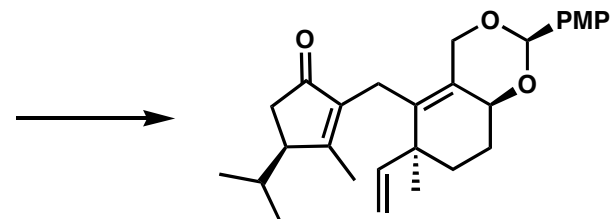

42

Stille product 42 (from Table 3): A vial was charged with $\mathrm{LiCl}(52 \mathrm{mg}, 1.23 \mathrm{mmol}$ ) and flame-dried. After cooling, tetrakis(triphenylphosphine)palladium (24 mg, $0.021 \mathrm{mmol}$ ) and cuprous chloride (102 mg, $1.03 \mathrm{mmol}$ ) were added and the solids were degassed (4x) under vacuum with an argon purge. Allylic acetate 41 (74 mg, $0.205 \mathrm{mmol})$ and vinylstannane 17 (68 $\mathrm{mg}, 0.23 \mathrm{mmol}$ ) were each added in $1.0 \mathrm{~mL}$ dry DMSO, and the 
solution was rigorously degassed $(4 \mathrm{x})$ by the freeze-pump-thaw method. The reaction was stirred at room temperature for $1 \mathrm{~h}$, then heated to $60{ }^{\circ} \mathrm{C}$. After $21 \mathrm{~h}$, when TLC showed consumption of the reactants, the reaction was treated with $\mathrm{H}_{2} \mathrm{O}$ and extracted with $\mathrm{Et}_{2} \mathrm{O}(3 \mathrm{x})$. The organic layer was dried over $\mathrm{MgSO}_{4}$, filtered, and concentrated. Purification of the crude product by flash chromatography $\left(\mathrm{SiO}_{2}, 5 \rightarrow 20 \%\right.$ EtOAc/hexanes) afforded $86 \mathrm{mg}(91 \%)$ of 42 as a white solid. $\mathrm{mp}=118{ }^{\circ} \mathrm{C}$; $\mathrm{TLC}: \mathrm{R}_{\mathrm{f}}=$ 0.61 (40\% EtOAc/hexanes); IR (film) 2957, 2361, 1698, 1616, 1517, 1249, 1095, 1034 $\mathrm{cm}^{-1} ;{ }^{1} \mathrm{H} \mathrm{NMR}\left(400 \mathrm{MHz}, \mathrm{CDCl}_{3}\right) \delta 7.41(\mathrm{~d}, J=8.8 \mathrm{~Hz}, 2 \mathrm{H}), 6.87(\mathrm{~d}, J=8.8 \mathrm{~Hz}, 2 \mathrm{H})$, $5.80(\mathrm{dd}, J=17.2,10.8 \mathrm{~Hz}, 1 \mathrm{H}), 5.62(\mathrm{~s}, 1 \mathrm{H}), 5.03(\mathrm{dd}, J=10.8,1.2 \mathrm{~Hz}, 1 \mathrm{H}), 4.98(\mathrm{dd}$, $J=17.2,1.2 \mathrm{~Hz}, 1 \mathrm{H}), 4.82(\mathrm{~d}, J=13.6 \mathrm{~Hz}, 1 \mathrm{H}), 4.44(\operatorname{app~t}, J=7.8 \mathrm{~Hz}, 1 \mathrm{H}), 4.26(\mathrm{~d}, J$ $=13.6 \mathrm{~Hz}, 1 \mathrm{H}), 3.78(\mathrm{~s}, 3 \mathrm{H}), 3.08(\mathrm{~d}, J=16.8 \mathrm{~Hz}, 1 \mathrm{H}), 2.86(\mathrm{~d}, J=16.8 \mathrm{~Hz}, 1 \mathrm{H}), 2.62$ (m, $1 \mathrm{H}), 2.19(\mathrm{dd}, J=18.8,6.4 \mathrm{~Hz}, 1 \mathrm{H}), 2.16(\mathrm{~m}, 1 \mathrm{H}), 2.07(\mathrm{dd}, J=18.8,2.4 \mathrm{~Hz}, 1 \mathrm{H})$, $2.01(\mathrm{~s}, 3 \mathrm{H}), 1.93(\mathrm{~m}, 1 \mathrm{H}), 1.86(\mathrm{~m}, 1 \mathrm{H}), 1.57(\mathrm{~m}, 1 \mathrm{H}), 1.54(\mathrm{~m}, 1 \mathrm{H}), 1.07(\mathrm{~s}, 3 \mathrm{H})$, $0.98(\mathrm{~d}, J=7.0 \mathrm{~Hz}, 3 \mathrm{H}), 0.59(\mathrm{~d}, J=7.0 \mathrm{~Hz}, 3 \mathrm{H}) ;{ }^{13} \mathrm{C} \mathrm{NMR}\left(100 \mathrm{MHz}, \mathrm{CDCl}_{3}\right) \delta$ $208.0,172.5,159.9,144.5,138.9,133.9,131.0,129.3,127.4,113.6,113.1,100.8,75.6$, $67.8,55.2,48.5,42.5,35.0,34.6,27.6,25.2,24.9,23.5,21.7,15.4,14.7 ;[\alpha]_{D}^{20}=+104.5$ $\left(\mathrm{c}=0.78, \mathrm{CHCl}_{3}\right) ; \mathrm{MS}(\mathrm{ESI})$ calculated for $[\mathrm{M}+\mathrm{Na}]^{+} 459$, found 459.

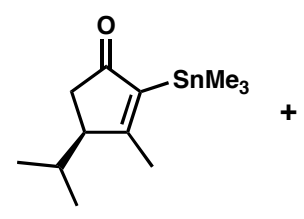

17

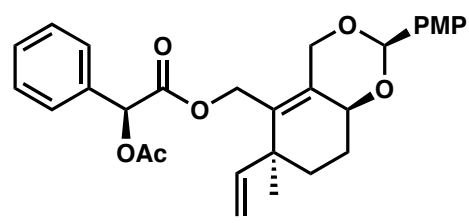

39

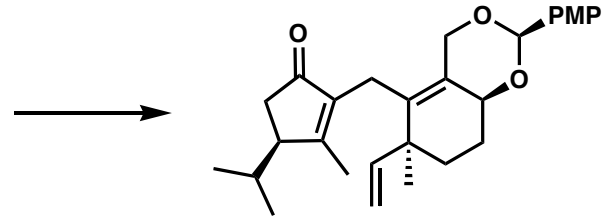

42

Stille product 42 (from Scheme 12): A vial was charged with $\mathrm{LiCl}$ (126 mg, $2.98 \mathrm{mmol}$ ) and flame-dried. After cooling, tetrakis(triphenylphosphine)palladium (57 mg, 0.05 
mmol) and cuprous chloride (246 $\mathrm{mg}, 2.48 \mathrm{mmol}$ ) were added and the solids were degassed (4x) under vacuum with an argon purge. Allylic mandelate 39 (178 mg, 0.36 mmol) and vinylstannane $17(164 \mathrm{mg}, 0.55 \mathrm{mmol})$ were each added in $2.5 \mathrm{~mL}$ dry DMSO, and the solution was rigorously degassed $(4 \mathrm{x})$ by the freeze-pump-thaw method. The reaction was stirred at room temperature for $1 \mathrm{~h}$, then heated to $60{ }^{\circ} \mathrm{C}$. After $17 \mathrm{~h}$, when TLC showed consumption of the reactants, the reaction was treated with $\mathrm{H}_{2} \mathrm{O}$ and extracted with $\mathrm{Et}_{2} \mathrm{O}(3 \mathrm{x})$. The organic layer was dried over $\mathrm{MgSO}_{4}$, filtered, and concentrated. Purification of the crude product by flash chromatography $\left(\mathrm{SiO}_{2}, 5 \rightarrow 15 \%\right.$ EtOAc/hexanes) afforded $122 \mathrm{mg}(78 \%)$ of $\mathbf{4 2}$ as a white solid.

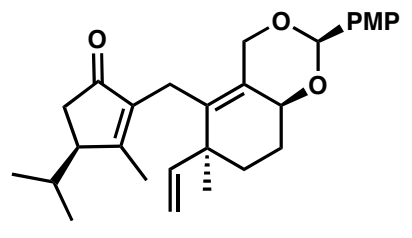

42

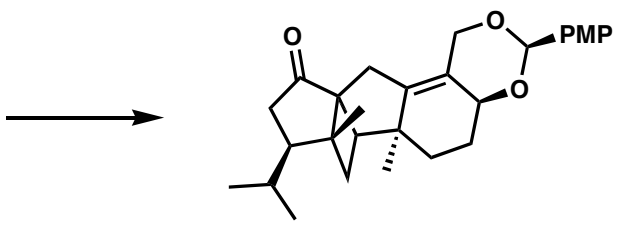

43

Cyclobutane 43 (Step a from Scheme 13): Enone olefin 42 (80 mg, $0.18 \mathrm{mmol})$ was dissolved in $3.6 \mathrm{~mL} \mathrm{Et}_{2} \mathrm{O}$ and placed in a quartz test tube. Diisopropylethylamine (12 $\mathrm{mg}, 16 \mu \mathrm{L}, 0.09 \mathrm{mmol}$ ) was added and the reaction was irradiated for $3 \mathrm{~h}$ with a $450 \mathrm{~W}$ Hanovia medium pressure mercury vapor lamp (no filter). The mixture was concentrated and purification by flash chromatography $\left(\mathrm{SiO}_{2}, 10 \%\right.$ EtOAc/hexanes) afforded $65.5 \mathrm{mg}$ (82\%) of cyclobutane $\mathbf{4 3}$ as a white foam. The yield of this reaction is sensitive to the purity of the starting material (white solid $\mathbf{4 2}$ consistently gave better yields than colored oils that appeared quite pure by ${ }^{1} \mathrm{H}$ NMR). TLC: $\mathrm{R}_{\mathrm{f}}=0.41$ (20\% EtOAc/hexanes); IR (film) $2957,1723,1615,1517,1248,1069,1035,992,826 \mathrm{~cm}^{-1} ;{ }^{1} \mathrm{H}$ NMR $(400 \mathrm{MHz}$, $\left.\mathrm{CDCl}_{3}\right) \delta 7.42(\mathrm{~d}, J=8.6 \mathrm{~Hz}, 2 \mathrm{H}), 6.89(\mathrm{~d}, J=8.6 \mathrm{~Hz}, 2 \mathrm{H}), 5.75(\mathrm{~s}, 1 \mathrm{H}), 4.71(\mathrm{~d}, J=$ 
$12.0 \mathrm{~Hz}, 1 \mathrm{H}), 4.32(\mathrm{~d}, J=12.0 \mathrm{~Hz}, 1 \mathrm{H}), 4.23(\mathrm{~m}, 1 \mathrm{H}), 3.79(\mathrm{~s}, 3 \mathrm{H}), 2.63($ app t, $1 \mathrm{H})$, 2.57 (m, 2 H), 2.05-1.97 (m, 3 H), 1.88-1.83 (m, 2 H), 1.72-1.53 (m, 3 H), 1.27-1.18 (m, $2 \mathrm{H}), 1.00(\mathrm{~d}, J=6.4 \mathrm{~Hz}, 3 \mathrm{H}), 0.96(\mathrm{~s}, 3 \mathrm{H}), 0.95(\mathrm{~s}, 3 \mathrm{H}), 0.93(\mathrm{~d}, J=6.4 \mathrm{~Hz}, 3 \mathrm{H}) ;{ }^{13} \mathrm{C}$ NMR (100 MHz, $\left.\mathrm{CDCl}_{3}\right) \delta$ 220.0, 159.9, 143.8, 131.9, 127.5, 124.1, 113.6, 102.2, 72.6, $68.3,62.8,55.2,51.6,51.3,44.7,43.3,42.2,34.4,30.0,28.3,25.7,25.1,23.0,22.4,22.3$, 15.7; $[\alpha]^{20}{ }_{D}=+13.8\left(\mathrm{c}=0.58, \mathrm{CHCl}_{3}\right)$; HRMS $(\mathrm{EI})$ calculated for $[\mathrm{M}]^{+} 436.2614$, found 436.2603.
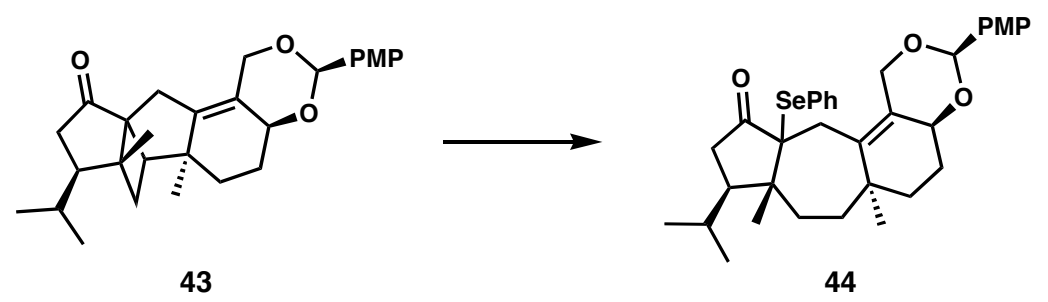

Selenide 44 (Step b from Scheme 13): Hexamethylphosphoric triamide (HMPA) (78 mg, $76 \mu \mathrm{L}, 0.44 \mathrm{mmol}$ ) was placed in a flame-dried vial and a blue $0.1 \mathrm{M}$ samarium diiodide solution in THF $(1.1 \mathrm{~mL}, 0.11 \mathrm{mmol})$ was added, changing the color of the solution to purple. Cyclobutyl ketone 43 (19 mg, $0.044 \mathrm{mmol})$ in $1.0 \mathrm{~mL}$ of dry, degassed THF was then added. After $15 \mathrm{~min}$, when TLC showed complete consumption of $\mathbf{4 3}$, phenylselenenyl bromide was added in $0.3 \mathrm{~mL}$ dry THF, and the reaction was stirred for 10 min more. Saturated aq. $\mathrm{NaHCO}_{3}$ was added to the reaction, and it was extracted with $\mathrm{CH}_{2} \mathrm{Cl}_{2}(3 \mathrm{x})$. Extracts were dried over $\mathrm{MgSO}_{4}$, filtered, and concentrated. Purification of the crude product by flash chromatography $\left(\mathrm{SiO}_{2}, 0 \rightarrow 10 \%\right.$ EtOAc/hexanes) afforded 13 $\mathrm{mg}(50 \%)$ of an inseparable mixture of diastereoisomers of $\mathbf{4 4}$ as a colorless oil. Selected data for the major isomer: TLC: $\mathrm{R}_{\mathrm{f}}=0.39\left(20 \% \mathrm{EtOAc} /\right.$ hexanes); ${ }^{1} \mathrm{H}$ NMR (400 MHz, $\left.\mathrm{CDCl}_{3}\right) \delta 5.49(\mathrm{~s}, 1 \mathrm{H}), 4.74(\mathrm{~d}, J=13.4 \mathrm{~Hz}, 1 \mathrm{H}), 4.31(\mathrm{~m}, 1 \mathrm{H}), 4.06(\mathrm{~d}, J=13.4 \mathrm{~Hz}, 1$ 
H), 3.77 (s, $3 \mathrm{H}), 3.27$ (d, $J=7.2 \mathrm{~Hz}, 1 \mathrm{H}), 3.23(\mathrm{~d}, J=7.2 \mathrm{~Hz}, 1 \mathrm{H}), 1.05(\mathrm{~d}, J=6.4 \mathrm{~Hz}$, $3 \mathrm{H}), 0.95(\mathrm{~d}, J=6.4 \mathrm{~Hz}, 3 \mathrm{H})$. MS (ESI) calculated for $[\mathrm{M}+\mathrm{Na}]^{+}$617, found 617.

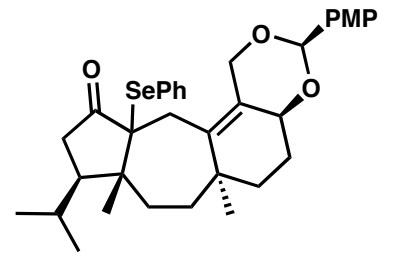

44

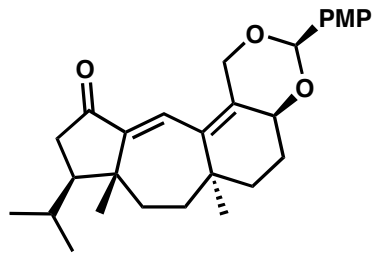

45

Dienone 45 (Step c from Scheme 13): Selenide 44 (10.4 mg, $0.018 \mathrm{mmol}$ ) in $0.7 \mathrm{ml}$ dry $\mathrm{CH}_{2} \mathrm{Cl}_{2}$ was cooled to $-78{ }^{\circ} \mathrm{C}$ and $m \mathrm{CPBA}(4.8 \mathrm{mg}, 0.019 \mathrm{mmol})$ in $0.2 \mathrm{~mL}$ dry $\mathrm{CH}_{2} \mathrm{Cl}_{2}$ was added dropwise. After $10 \mathrm{~min}$, when TLC showed complete consumption of compound 44 , the reaction was quenched at $-78{ }^{\circ} \mathrm{C}$ with saturated aq. $\mathrm{Na}_{2} \mathrm{~S}_{2} \mathrm{O}_{3}$. The mixture was allowed to warm to rt and saturated aq. $\mathrm{NaHCO}_{3}$ was added. The mixture was extracted with $\mathrm{CH}_{2} \mathrm{Cl}_{2}(3 \mathrm{x})$. Extracts were dried over $\mathrm{MgSO}_{4}$, filtered, and concentrated. Purification of the crude product by flash chromatography $\left(\mathrm{SiO}_{2}, 10 \rightarrow\right.$ $15 \%$ EtOAc/hexanes) afforded $6.6 \mathrm{mg}(86 \%)$ of $\mathbf{4 5}$ as a colorless oil. TLC: $\mathrm{R}_{\mathrm{f}}=0.36$ (20\% EtOAc/hexanes); IR (film) 2956, 1716, 1616, 1517, 1249, 1099, 1033, $829 \mathrm{~cm}^{-1} ;{ }^{1} \mathrm{H}$ NMR (400 MHz, $\left.\mathrm{CDCl}_{3}\right) \delta 7.40(\mathrm{~d}, J=8.8 \mathrm{~Hz}, 2 \mathrm{H}), 6.96(\mathrm{~s}, 1 \mathrm{H}), 6.87$ (d, $J=8.8 \mathrm{~Hz}, 2$ H), $5.60(\mathrm{~s}, 1 \mathrm{H}), 4.66(\mathrm{~d}, J=12.8 \mathrm{~Hz}, 1 \mathrm{H}), 4.44(\operatorname{app~t}, J=7.2 \mathrm{~Hz}, 1 \mathrm{H}), 4.36(\mathrm{~d}, J=$ $12.8 \mathrm{~Hz}, 1 \mathrm{H}), 3.79(\mathrm{~s}, 3 \mathrm{H}), 2.50(\mathrm{dd}, J=18.2,7.4 \mathrm{~Hz}, 1 \mathrm{H}), 2.41-2.29(\mathrm{~m}, 1 \mathrm{H}), 2.17$ (dd, $J=18.0 \mathrm{~Hz}, 13.6 \mathrm{~Hz}, 1 \mathrm{H}), 2.08-1.75(\mathrm{~m}, 6 \mathrm{H}), 1.67-1.55(\mathrm{~m}, 2 \mathrm{H}), 1.43-1.36(\mathrm{~m}, 1$ H), $1.12(\mathrm{~s}, 3 \mathrm{H}), 1.04(\mathrm{~d}, J=6.4 \mathrm{~Hz}, 3 \mathrm{H}), 0.96(\mathrm{~s}, 3 \mathrm{H}), 0.94(\mathrm{~d}, J=6.4 \mathrm{~Hz}, 3 \mathrm{H}) ;{ }^{13} \mathrm{C}$ NMR (100 MHz, $\left.\mathrm{CDCl}_{3}\right) \delta$ 205.3, 159.9, 147.5, 136.3, 131.0, 130.8, 130.4, 127.4, 113.6, $100.6,75.3,67.2,55.3,51.4,46.2,41.3,36.8,36.4,34.0,29.7,28.5,26.6,25.2,24.1$, 
22.3, 11.0; $[\alpha]^{20}{ }_{\mathrm{D}}=-43.7\left(\mathrm{c}=0.46, \mathrm{CHCl}_{3}\right)$; HRMS $(\mathrm{EI})$ calculated for $[\mathrm{M}]^{+} 436.2614$, found 436.2634 .

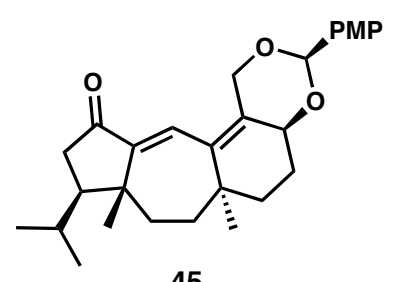

45

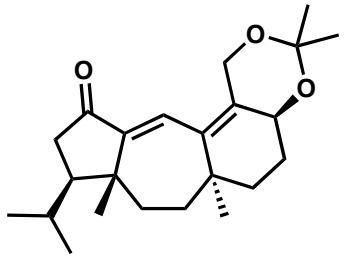

49

Isopropylidene ketal 49 (Step a from Scheme 16): Benzylidene acetal 45 (4.1 mg, $0.0094 \mathrm{mmol}$ ) was dissolved in $0.4 \mathrm{~mL}$ of 2,2-dimethoxy propane. Pyridinium $p$ toluenesulfonate $(0.5 \mathrm{mg}, 0.0019 \mathrm{mmol})$ was added and the mixture was heated at $60{ }^{\circ} \mathrm{C}$ for $20 \mathrm{~h}$. The mixture was treated with saturated aq. $\mathrm{NaHCO}_{3}$ and extracted with $\mathrm{Et}_{2} \mathrm{O}$ (3x). Extracts were dried over $\mathrm{MgSO}_{4}$, filtered, and concentrated. Purification of the crude product by flash chromatography $\left(\mathrm{SiO}_{2}, 10 \%\right.$ EtOAc/hexanes) afforded $2.6 \mathrm{mg}$ (77\%) of compound 49 as a colorless oil. The ${ }^{1} \mathrm{H}$ and ${ }^{13} \mathrm{C}$ NMR spectra are identical to those supplied by the Snider group (see: Shi, B.; Hawryluk, N. A.; Snider, B. B. J. Org. Chem. 2003, 68, 1030-1042.) TLC: $\mathrm{R}_{\mathrm{f}}=0.50$ (20\% EtOAc/hexanes); IR (film) 2960, $1717,1620,1456,1379,1261,1222,1175,1091,1023,867,801 \mathrm{~cm}^{-1} ;{ }^{1} \mathrm{H}$ NMR $(400$ $\left.\mathrm{MHz}, \mathrm{CDCl}_{3}\right) \delta 6.81(\mathrm{~s}, 1 \mathrm{H}), 4.36(\mathrm{~d}, J=15.8 \mathrm{~Hz}, 1 \mathrm{H}), 4.34(\mathrm{~m}, 1 \mathrm{H}), 4.07(\mathrm{~d}, J=15.8$ $\mathrm{Hz}, 1 \mathrm{H}), 2.49(\mathrm{dd}, J=18.0,7.6 \mathrm{~Hz}, 1 \mathrm{H}), 2.26(\operatorname{app} \mathrm{dt}, J=13.6,1.6 \mathrm{~Hz}, 1 \mathrm{H}), 2.14(\mathrm{dd}, J$ $=18.2,13.4 \mathrm{~Hz}, 1 \mathrm{H}), 1.98-1.84,(\mathrm{~m}, 2 \mathrm{H}), 1.83-1.71(\mathrm{~m}, 2 \mathrm{H}), 1.69-1.56(\mathrm{~m}, 4 \mathrm{H}), 1.43$ (s, $3 \mathrm{H}), 1.39-1.32(\mathrm{~m}, 1 \mathrm{H}), 1.35(\mathrm{~s}, 3 \mathrm{H}), 1.04(\mathrm{~d}, J=6.8 \mathrm{~Hz}, 3 \mathrm{H}), 1.01(\mathrm{~s}, 3 \mathrm{H}), 0.95(\mathrm{~s}$, $3 \mathrm{H}), 0.93(\mathrm{~d}, J=6.8 \mathrm{~Hz}, 3 \mathrm{H}) ;{ }^{13} \mathrm{C} \mathrm{NMR}\left(100 \mathrm{MHz}, \mathrm{CDCl}_{3}\right) \delta 205.4,146.4,139.7$, 133.1, 129.5, 100.1, 67.6, 60.1, 51.4, 46.1, 41.2, 38.2, 36.9, 36.4, 33.8, 28.5, 26.9, 25.0, 
24.5, 24.2, 23.9, 22.3, 17.9; $[\alpha]_{\mathrm{D}}^{20}=-144.5\left(\mathrm{c}=0.31, \mathrm{CHCl}_{3}\right)$; HRMS (EI) calculated for $[\mathrm{M}]^{+}$358.2508, found 358.2491.

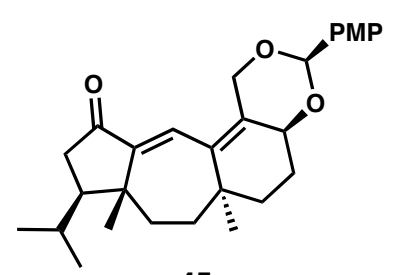

45

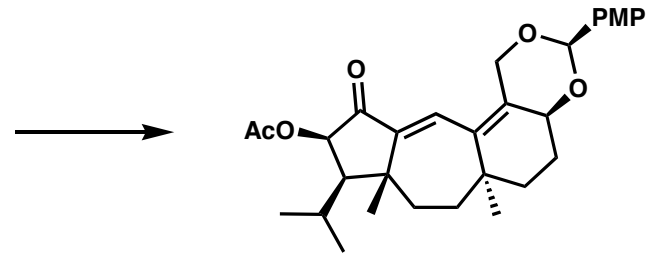

52

Acetate ester 52 (Steps a-c from Scheme 17): Dienone 45 (14 mg, $0.032 \mathrm{mmol}$ ) was dissolved in $1.6 \mathrm{~mL}$ dry $\mathrm{CH}_{2} \mathrm{Cl}_{2}$ and cooled to $-78^{\circ} \mathrm{C}$. Triethylamine $(32 \mathrm{mg}, 45 \mu \mathrm{L}$, $0.32 \mathrm{mmol}$ ) was added, followed by triethylsilyl trifluoromethanesulfonate. After 15 min, when TLC showed clean conversion to the triethylsilyl enol ether $\left(R_{f}=0.61,20 \%\right.$ EtOAc/hexanes), the mixture was diluted with $5 \mathrm{~mL}$ EtOAc, washed with $1 \mathrm{~mL}$ saturated aq. $\mathrm{NaHCO}_{3}$, dried over $\mathrm{Na}_{2} \mathrm{SO}_{4}$, and concentrated to give an oil. The oil was dissolved in $0.6 \mathrm{~mL} \mathrm{CH}_{2} \mathrm{Cl}_{2}$, solid $\mathrm{NaHCO}_{3}$ was added $(6.7 \mathrm{mg}, 0.08 \mathrm{mmol})$, and the mixture was cooled to $-78^{\circ} \mathrm{C}$. A solution of $m \mathrm{CPBA}(9.5 \mathrm{mg}, 0.039 \mathrm{mmol})$ in $\mathrm{CH}_{2} \mathrm{Cl}_{2}$ was added and the mixture was stirred for $1 \mathrm{~h}$. The reaction was quenched at $-78^{\circ} \mathrm{C}$ with saturated aq. $\mathrm{Na}_{2} \mathrm{~S}_{2} \mathrm{O}_{3}$ and saturated aq. $\mathrm{NaHCO}_{3}$ and extracted with $\mathrm{CH}_{2} \mathrm{Cl}_{2}(3 \mathrm{x})$. The extracts were dried over $\mathrm{MgSO}_{4}$ and concentrated to give a pale yellow oil. The material could be purified by silica gel chromatography $\left(\mathrm{R}_{\mathrm{f}}=0.14,20 \%\right.$ EtOAc/hexanes $)$, but was usually carried forward in crude form because of concern over the stability of $\alpha$-hydroxy ketone $51\left(\mathrm{R}_{\mathrm{f}}=0.18,25 \%\right.$ EtOAc/hexanes $)$. The pale yellow oil was dissolved in $0.6 \mathrm{~mL}$ $\mathrm{CH}_{2} \mathrm{Cl}_{2}$, and pyridine $(20 \mu \mathrm{L}, 0.24 \mathrm{mmol})$, DMAP $(0.3 \mathrm{mg}, 0.0024 \mathrm{mmol})$, and acetic anhydride (12 mL, $0.12 \mathrm{mmol})$ were added. After $15 \mathrm{~min}$, TLC showed consumption of the starting material. The mixture was azeotropically treated with heptane $(3 \mathrm{x})$, filtered 
through a pad of silica (EtOAc), and concentrated. The crude material was purified by flash chromatography $\left(\mathrm{SiO}_{2}, 2-4 \% \mathrm{EtOAc} / \mathrm{CH}_{2} \mathrm{Cl}_{2}\right)$ to give $7.2 \mathrm{mg}$ (45\% over 3 steps) of acetate ester $\mathbf{5 2}$ as a colorless oil. TLC: $\mathbf{R}_{\mathrm{f}}=0.38$ (30\% EtOAc/hexanes); IR (film) 2923, 1748, 1614, 1248, 1216, 1094, $1033 \mathrm{~cm}^{-1} ;{ }^{1} \mathrm{H}$ NMR $\left(400 \mathrm{MHz}, \mathrm{CDCl}_{3}\right) \delta 7.41(\mathrm{~d}, J=8.8$ $\mathrm{Hz}, 2 \mathrm{H}), 7.11(\mathrm{br} \mathrm{s}, 1 \mathrm{H}), 6.88(\mathrm{~d}, J=8.8 \mathrm{~Hz}, 2 \mathrm{H}), 5.61(\mathrm{~s}, 1 \mathrm{H}), 5.44(\mathrm{~d}, J=6.0 \mathrm{~Hz}, 1$ H), $4.67(\mathrm{~d}, J=12.8 \mathrm{~Hz}, 1 \mathrm{H}), 4.46(\operatorname{app~t}, J=7.8 \mathrm{~Hz}, 1 \mathrm{H}), 4.38(\mathrm{~d}, J=12.8 \mathrm{~Hz}, 1 \mathrm{H})$, $3.79(\mathrm{~s}, 3 \mathrm{H}), 2.40(\mathrm{~m}, 1 \mathrm{H}), 2.10(\mathrm{~s}, 3 \mathrm{H}), 2.07-1.87$ (m, $5 \mathrm{H}), 1.75(\mathrm{~m}, 1 \mathrm{H}), 1.62-1.56$ (m, $2 \mathrm{H}), 1.39(\mathrm{~m}, 1 \mathrm{H}), 1.32(\mathrm{~s}, 3 \mathrm{H}), 1.10(\mathrm{~d}, J=6.4 \mathrm{~Hz}, 3 \mathrm{H}), 0.95(\mathrm{~s}, 3 \mathrm{H}), 0.94(\mathrm{~d}, J=$ $6.4 \mathrm{~Hz}, 3 \mathrm{H}) ;{ }^{13} \mathrm{C}$ NMR $\left(100 \mathrm{MHz}, \mathrm{CDCl}_{3}\right) \delta 199.5,169.5,160.0,146.1,136.0,134.4$, $131.5,130.7,127.4,113.7,100.6,75.2,74.4,67.2,55.3,45.6,36.6,36.2,34.2,29.7,29.7$, 26.7, 25.2, 24.8, 23.3, 22.9, 21.0, 20.9; $[\alpha]_{\mathrm{D}}^{20}=+28.2\left(\mathrm{c}=0.22, \mathrm{CHCl}_{3}\right) ; \mathrm{HRMS}(\mathrm{EI})$ calculated for $[\mathrm{M}]^{+}$494.2668, found 494.2679.
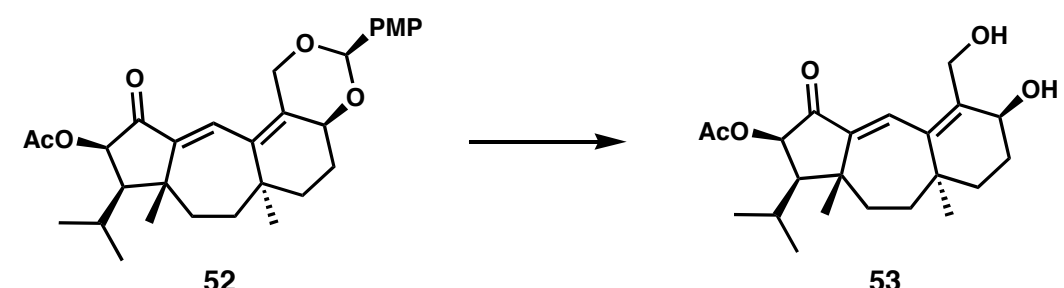

Diol 53 (Step a from Scheme 18): Benzylidene acetal 52 (3.0 mg, $0.0061 \mathrm{mmol})$ was dissolved in $0.3 \mathrm{~mL} \mathrm{MeOH.} \mathrm{Pyridinium} p$-toluenesulfonic acid (0.4 mg, $0.0015 \mathrm{mmol}$ ) was added and the mixture was stirred for $30 \mathrm{~min}$ at $70{ }^{\circ} \mathrm{C}$. The mixture was cooled to rt, and all solvent was removed with a stream of $\mathrm{N}_{2}$. The crude material was purified by flash chromatography $\left(\mathrm{SiO}_{2}, 40-60 \%\right.$ EtOAc/hexanes $)$ to give $2.0 \mathrm{mg}(88 \%)$ of unstable diol $\mathbf{5 3}$ as a colorless oil. The diol $\mathbf{5 3}$ was not stable to storage and was immediately used in the next step. TLC: $\mathrm{R}_{\mathrm{f}}=0.21$ (60\% EtOAc/hexanes). 


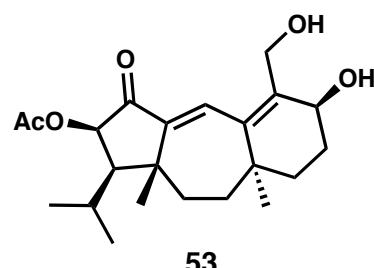

53

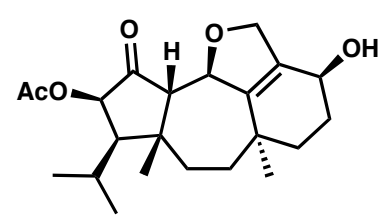

3: (+)-Guanacastepene E

3: (+)-Guanacastepene E: Diol 53 (2.9 mg, $0.0077 \mathrm{mmol})$ was dissolved in $0.4 \mathrm{~mL}$ dry $\mathrm{CH}_{2} \mathrm{Cl}_{2}$. Silica gel was added and the slurry was stirred for $36 \mathrm{~h}$. Silica gel was then filtered off with EtOAc, and the solution was concentrated under a stream of $\mathrm{N}_{2}$. The crude material, which consisted of diol $\mathbf{5 3}$ and (+)-guanacastepene E (3), was purified by preparative thin layer chromatography (100\% EtOAc), yielding $1.7 \mathrm{mg}(59 \%)$ of (+)guanacastepene E (3) and $1.0 \mathrm{mg}(34 \%)$ of diol $\mathbf{5 3}$ which could be recycled. TLC: $\mathrm{R}_{\mathrm{f}}=$ 0.27 (70\% EtOAc/hexanes); IR (film) 3401, 2925, 2853, 1750, 1457, 1373, 1226, 1055 $\mathrm{cm}^{-1} ;{ }^{1} \mathrm{H}$ NMR $\left(500 \mathrm{MHz}\right.$, acetone-d $\left.{ }_{6}\right) \delta 5.63(\mathrm{~d}, J=9.5 \mathrm{~Hz}, 1 \mathrm{H}), 5.14(\mathrm{dd}, J=10.0,5.0$ $\mathrm{Hz}, 1 \mathrm{H}), 4.69$ (dd, $J=12.0,5.0 \mathrm{~Hz}, 1 \mathrm{H}), 4.36$ (d, $J=11.5 \mathrm{~Hz}, 1 \mathrm{H}), 4.15$ (br m, $1 \mathrm{H})$, $3.93(\mathrm{~d}, J=7.0 \mathrm{~Hz}, 1 \mathrm{H}), 2.47(\operatorname{app~t}, J=9.8 \mathrm{~Hz}, 1 \mathrm{H}), 2.12(\mathrm{~s}, 3 \mathrm{H}), 1.97(\mathrm{~m}, 3 \mathrm{H}), 1.81-$ 1.73 (m, $3 \mathrm{H}), 1.49$ (m, $2 \mathrm{H}), 1.39$ (m, $2 \mathrm{H}), 1.12$ (d, J = 6.5 Hz, $3 \mathrm{H}), 1.10$ (s, $3 \mathrm{H}), 1.02$ (s, $3 \mathrm{H}), 0.92(\mathrm{~d}, J=6.5 \mathrm{~Hz}, 3 \mathrm{H}) ;{ }^{13} \mathrm{C}$ NMR (125 MHz, acetone-d $\left.)_{6}\right)$ The following fourteen ${ }^{13} \mathrm{C}$ signals that we observed are in agreement with Clardy's data. $\delta 144.6,81.5$, $74.1,67.6,61.4,44.5,36.6,34.6,34.5,26.4,23.6,23.3,23.0,20.7 ;[\alpha]^{20}{ }_{D}=+25.9(\mathrm{c}=$ 0.17, $\mathrm{CHCl}_{3}$ ); HRMS (ESI-TOF) calculated for $[\mathrm{M}+\mathrm{Na}]^{+}$399.2142, found 399.2139. 


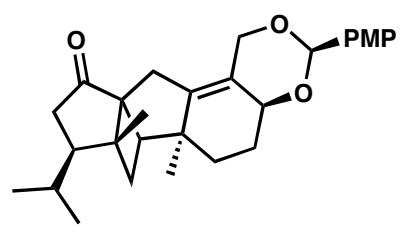

3.30

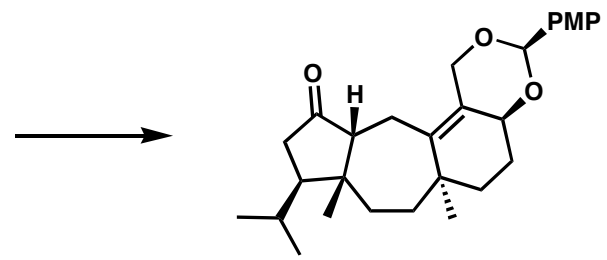

E.2

Ketone E.2 (from the Ph. D. thesis of William D. Shipe, The Scripps Research Institute, 2004): Hexamethylphosphoric triamide (HMPA) (70 mg, $68 \mu \mathrm{L}, 0.39 \mathrm{mmol}$ ) was placed in a flame-dried vial and a blue $0.1 \mathrm{M}$ samarium diiodide solution in THF $(1.0 \mathrm{~mL}, 0.10$ mmol) was added, changing the color of the solution to purple. Cyclobutyl ketone 3.30 (17 mg, $0.039 \mathrm{mmol}$ ) in $1.0 \mathrm{~mL}$ of dry, degassed THF was then added. After $15 \mathrm{~min}$, when TLC showed complete consumption of $\mathbf{3 . 3 0}$, the reaction was opened to the air to quench the reducing agent. Saturated aq. $\mathrm{NaHCO}_{3}$ was added to the reaction, and it was extracted with $\mathrm{CH}_{2} \mathrm{Cl}_{2}(3 \mathrm{x})$. Extracts were dried over $\mathrm{MgSO}_{4}$, filtered, and concentrated. Purification of the crude product by flash chromatography $\left(\mathrm{SiO}_{2}, 0 \rightarrow 10 \%\right.$ EtOAc/hexanes) afforded $10.8 \mathrm{mg}(63 \%)$ of a $6.5: 1$ mixture of diastereoisomers of ketone E.2 as a colorless oil. Data for major diastereoisomer: TLC: $R_{\mathrm{f}}=0.37(20 \%$ EtOAc/hexanes); IR (film) 2923, 1735, 1516, 1247, $1098 \mathrm{~cm}^{-1} ;{ }^{1} \mathrm{H}$ NMR (400 MHz, $\left.\mathrm{CDCl}_{3}\right) \delta 7.40(\mathrm{~d}, J=8.8 \mathrm{~Hz}, 2 \mathrm{H}), 6.87(\mathrm{~d}, J=8.8 \mathrm{~Hz}, 2 \mathrm{H}), 5.59(\mathrm{~s}, 1 \mathrm{H}), 4.99(\mathrm{~d}, J=$ $13.6 \mathrm{~Hz}, 1 \mathrm{H}), 4.38(\operatorname{app~t}, J=6.6 \mathrm{~Hz}, 1 \mathrm{H}), 4.19(\mathrm{~d}, J=13.6 \mathrm{~Hz}, 1 \mathrm{H}), 3.79$ (s, $3 \mathrm{H}), 2.61$ (dd, $J=16.6,9.8 \mathrm{~Hz}, 1 \mathrm{H}), 2.46(\mathrm{~m}, 2 \mathrm{H}), 2.28(\mathrm{~m}, 1 \mathrm{H}), 2.11(\mathrm{~m}, 2 \mathrm{H}), 1.95(\mathrm{~m}, 3 \mathrm{H})$, $1.74(\mathrm{~m}, 1 \mathrm{H}), 1.63(\mathrm{~m}, 2 \mathrm{H}), 1.54(\mathrm{~m}, 2 \mathrm{H}), 1.36(\mathrm{~m}, 1 \mathrm{H}), 1.06(\mathrm{~s}, 3 \mathrm{H}), 1.04(\mathrm{~d}, J=6.4$ $\mathrm{Hz}, 3 \mathrm{H}), 0.90(\mathrm{~d}, J=6.4 \mathrm{~Hz}, 3 \mathrm{H}), 0.84(\mathrm{~s}, 3 \mathrm{H}) ;{ }^{13} \mathrm{C} \mathrm{NMR}\left(100 \mathrm{MHz}, \mathrm{CDCl}_{3}\right) \delta 206.2$, $159.9,137.6,131.1,127.5,125.9,113.6,100.8,75.9,67.1,59.3,55.3,51.8,46.1,40.0$, $39.3,38.4,38.1,37.5,29.0,25.1,25.0,24.2,24.2,22.3,12.4 ;[\alpha]^{20}{ }_{D}=+107.0(\mathrm{c}=0.79$, $\mathrm{CHCl}_{3}$ ); HRMS (MALDI-FTMS) calculated for $[\mathrm{M}]^{+}$438.2770, found 438.2780. 
Observations on the synthesis of vinyl stannane 17:

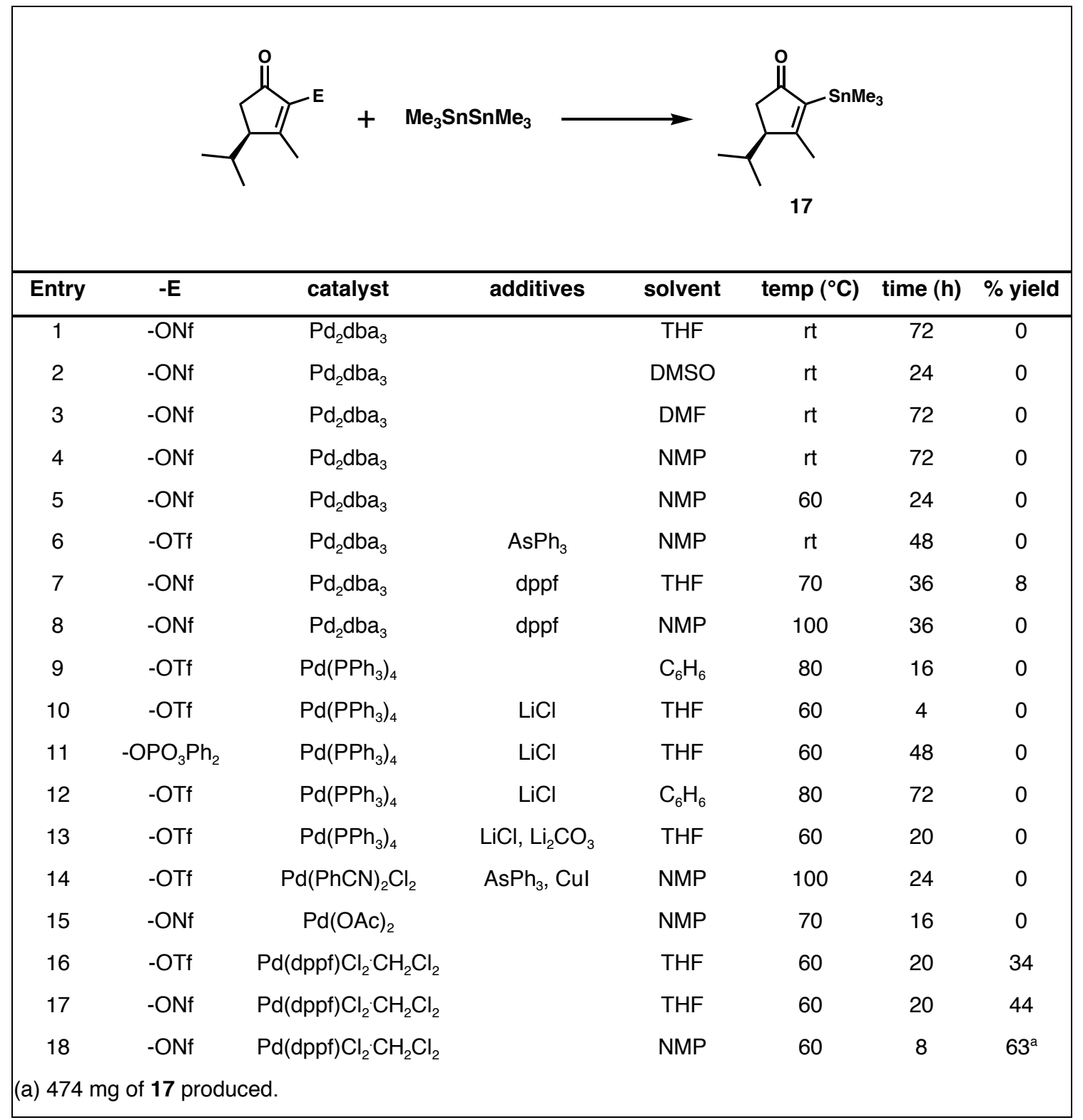

Table 1. Reaction conditions screened for the Wulff-Stille synthesis of vinylstannane 17. NMP = 1methyl-2-pyrrolidinone; $\mathrm{dppf}=1,1^{\prime}$-bis(diphenylphosphino)ferrocene; $\mathrm{dba}=$ trans, transdibenzylideneacetone; $\mathrm{rt}=$ room temperature.

Observations on the $\pi$-allyl Stille coupling of compounds 17 and 41: 


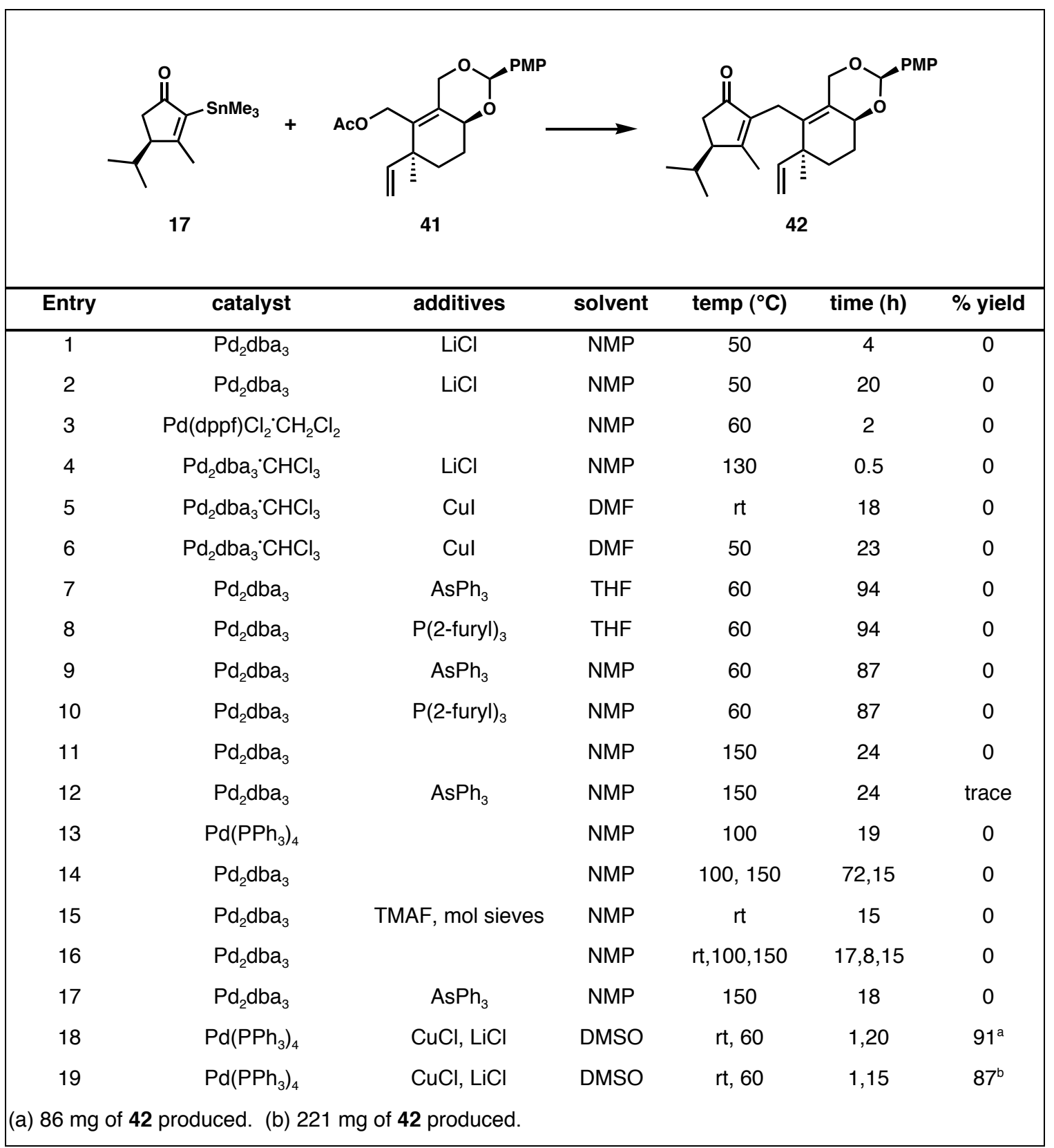

Table 3. Some conditions screened for the $\pi$-allyl Stille cross-coupling of $\mathbf{1 7}$ and $\mathbf{4 1}$.

\section{A complete listing of authors for reference \#22c:}

Deslongchamps, P.; Bélanger, A.; Berney, D. J. F.; Borschberg, H.-J.; Brousseau, R.; Doutheau, A.; Durand, R.; Katayama, H.; Lapalme, R.; Leturc, D. M.; Liao, C.-C.; 
MacLachlan, F. N.; Maffrand, J.-P.; Marazza, F.; Matrino, R.; Moreau, C.; Ruest, L.;

Saint-Laurent, L.; Saintonge, R.; Soucy, P. Can. J. Chem. 1990, 68, 127-152. 